\title{
Enhanced Accident Tolerant LWR Fuels National Metrics Workshop Report
}

\author{
Lori Braase
}

January 2013

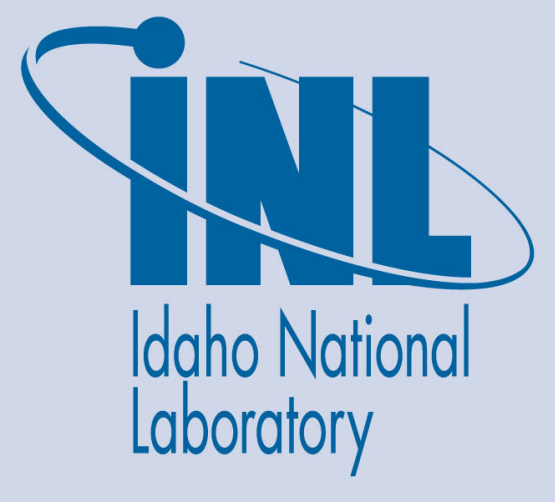

The INL is a U.S. Department of Energy National Laboratory operated by Battelle Energy Alliance 
INL/EXT-13-28090

FCRD-FUEL-2013-000087

\title{
Enhanced Accident Tolerant LWR Fuels National Metrics Workshop Report
}

\author{
Lori Braase
}

January 2013

\section{Idaho National Laboratory \\ Fuel Cycle Research \& Development Idaho Falls, Idaho 83415}

http://www.inl.gov

Prepared for the

U.S. Department of Energy

Office of Nuclear Energy

Under DOE Idaho Operations Office

Contract DE-AC07-05ID14517 


\section{DISCLAIMER}

This information was prepared as an account of work sponsored by an agency of the U.S. Government. Neither the U.S. Government nor any agency thereof, nor any of their employees, makes any warranty, expressed or implied, or assumes any legal liability or responsibility for the accuracy, completeness, or usefulness, of any information, apparatus, product, or process disclosed, or represents that its use would not infringe privately owned rights. References herein to any specific commercial product, process, or service by trade name, trade mark, manufacturer, or otherwise, does not necessarily constitute or imply its endorsement, recommendation, or favoring by the U.S. Government or any agency thereof. The views and opinions of authors expressed herein do not necessarily state or reflect those of the U.S. Government or any agency thereof. 


\section{Prepared by:}

Lori Braase, Idaho National Laboratory (INL)

Advanced Fuels Campaign (AFC)

\section{Reviewed by:}

Shannon Bragg-Sitton, Idaho National Laboratory (INL)

Light Water Reactor Sustainability (LWRS)/Advanced Fuels Campaign (AFC)

Chris Stanek, Los Alamos National Laboratory (LANL)

Consortium for Advanced Simulation of Light Water Reactors (CASL)

Rose Montgomery, Tennessee Valley Authority (TVA)

Utility

\section{Approved by:}

AFC National Technical Director

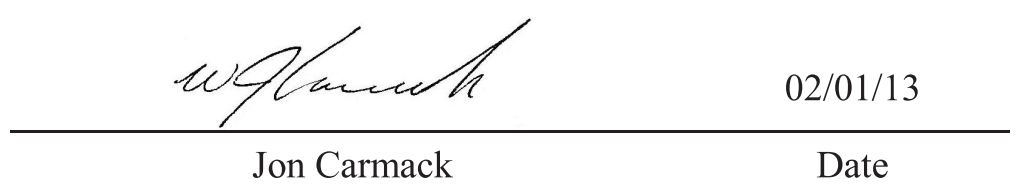




\section{EXECUTIVE SUMMARY}

The U.S. Department of Energy Office of Nuclear Energy (DOE-NE), in collaboration with the nuclear industry, has been conducting research and development (R\&D) activities on advanced Light Water Reactor (LWR) fuels for the last few years. The emphasis for these activities was on improving the fuel performance in terms of increased burnup for waste minimization and increased power density for power upgrades, as well as collaborating with industry on fuel reliability.

After the events at the Fukushima Nuclear Power Plant in Japan in March 2011, enhancing the accident tolerance of LWRs became a topic of serious discussion. In the Consolidated Appropriations Act, 2012, Conference Report 112-75, the U.S. Congress directed DOE-NE to:

- Give "priority to developing enhanced fuels and cladding for light water reactors to improve safety in the event of accidents in the reactor or spent fuel pools."

- Give "special technical emphasis and funding priority...to activities aimed at the development and near-term qualification of meltdown-resistant, accident-tolerant nuclear fuels that would enhance the safety of present and future generations of light water reactors."

- Report "to the Committee, within 90 days of enactment of this act, on its plan for development of meltdown-resistant fuels leading to reactor testing and utilization by 2020."

As a result, the pre-decisional draft roadmap, "Development of Light Water Reactor Fuels with Enhanced Accident Tolerance - Report to Congress," was written; however, the document has not been issued pending Congressional approval.

The roadmap focuses on the development of advanced LWR fuels with enhanced accident tolerance. The vision is to have a "LWR fleet with enhanced accident tolerance providing a substantial fraction of the national

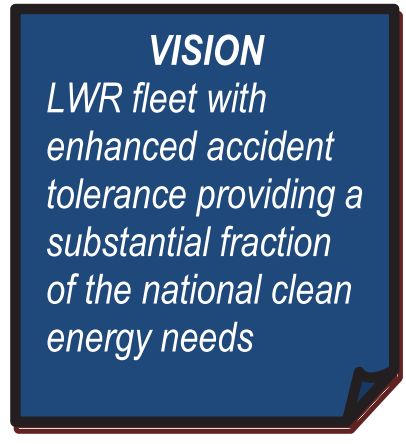
clean energy needs." New fuel concepts will be evaluated with respect to the accident scenarios and specific plan designs for LWRs. As development progresses, the new advanced fuels must be evaluated within the context of the other potential improvements to enhance overall safety (e.g., access to emergency cooling water, additional battery power, etc.).

The DOE Fuel Cycle Research and Development (FCRD) Advanced Fuels Campaign (AFC) was reorganized at the beginning of FY-13 to include research, development, and demonstration (RD\&D) on Accident Tolerant Fuels (ATF). This mission emphasizes the development of novel fuel and cladding concepts to replace the current zirconium alloyuranium dioxide $\left(\mathrm{UO}_{2}\right)$ fuel system. The initial effort will focus on applications in operating reactors or reactors with design certifications. The goal is to insert a lead test assembly (LTA) or lead test rod (LTR) into a commercial reactor within ten years (i.e. by 2022).

MISSION Develop advanced fuels/cladding and non-design intrusive reactor system technologies (e.g. instruments, auxiliary power sources) with improved performance, reliability and safety characteristics during normal operations and accident conditions, while minimizing waste generation. 
Fuels with enhanced accident tolerance are those that, in comparison with the standard $\mathrm{UO}_{2}$-zirconium alloy system currently used by the nuclear industry, can tolerate loss of active cooling in the reactor core for a considerably longer time period (depending on the LWR system and accident scenario) while maintaining or improving the fuel performance during normal operations, and operational transients, as well as design-basis and beyond design-basis events.

The overall draft strategy for development and demonstration is comprised of three phases: Feasibility Assessment and Down-selection; Development and Qualification; and Commercialization. The activities performed during the feasibility assessment phase include laboratory scale experiments; fuel performance code updates; and analytical assessment of economic, operational, safety, fuel cycle, and environmental impacts of the new concepts. The development and qualification stage will consist of fuel fabrication and large scale irradiation and safety basis testing, leading to qualification and ultimate NRC licensing of the new fuel. The commercialization phase initiates technology transfer to industry for implementation.

Attributes for fuels with enhanced accident tolerance include improved reaction kinetics with steam and slower hydrogen generation rate, while maintaining acceptable cladding thermo-mechanical properties; fuel thermo-mechanical properties; fuel-clad interactions; and fission-product behavior. These attributes provide a qualitative guidance for parameters that must be considered in the development of fuels and cladding with enhanced accident tolerance. However, quantitative metrics must be developed for these attributes.

Any new fuel concept proposed for enhanced accident tolerance under rare events must comply with current operational, economic, and safety constraints, as well as fuel cycle impacts and current LWR design constraints. The early phases of the implementation will require considerable analyses support to assess the impacts of the novel concepts.

To initiate the quantitative metrics development, a Light Water Reactor Enhanced Accident Tolerant Fuels Metrics Development Workshop was held October 10-11, 2012, in Germantown, Maryland. This document summarizes the structure and outcome of the two-day workshop. Questions regarding the content can be directed to Lori Braase, 208-526-7763, lori.braase@inl.gov. 


\section{CONTENTS}

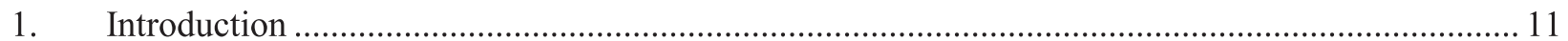

1.1 Challenges in Developing Accident Tolerant Fuel ...................................................... 12

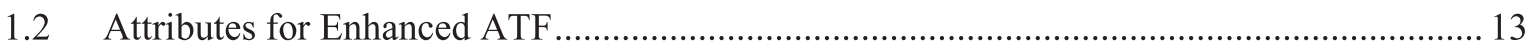

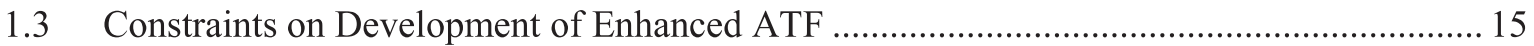

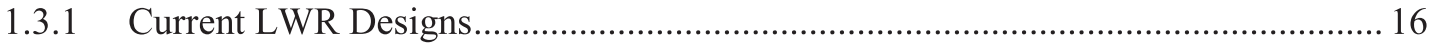

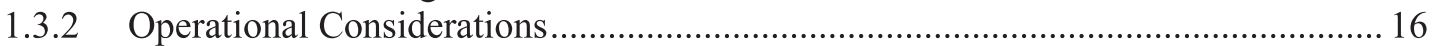

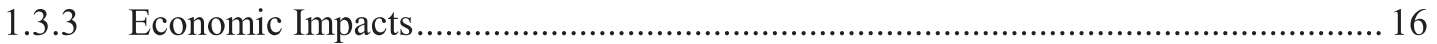

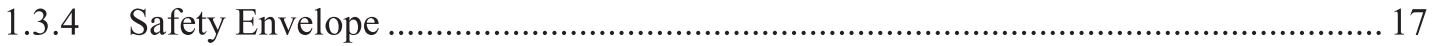

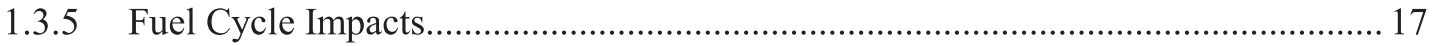

1.4 NRC Guidance on Reactor Operating Condition Definitions ............................................. 17

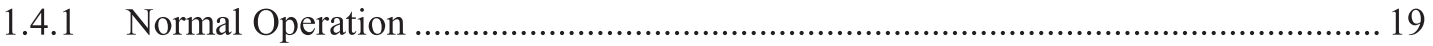

1.4.2 Overpower Anticipated Operation Occurrence................................................. 19

1.4.3 Decrease in Coolant Flow Anticipated Operation Occurrence ................................ 19

1.4.4 Reactivity Initiated Accident (RIA) Design Basis Accident................................... 19

1.4.5 Loss of Coolant Accident (LOCA) Design Basis Accident ..................................... 20

1.4.6 Severe Accidents (with and without quench) ...................................................... 21

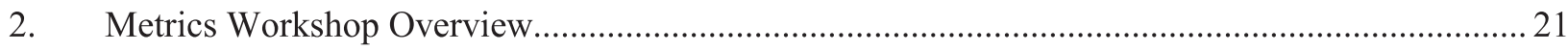

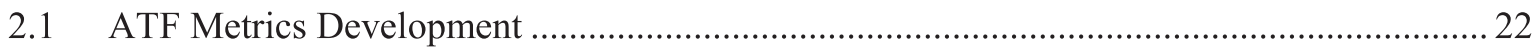

3. Breakout Session Summary: Advanced Nuclear Fuel Cladding …........................................... 23

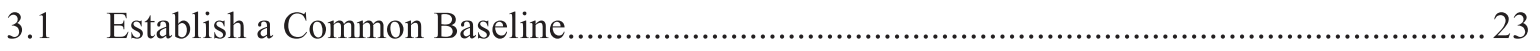

3.2 Attributes for Advanced Cladding Options................................................................... 28

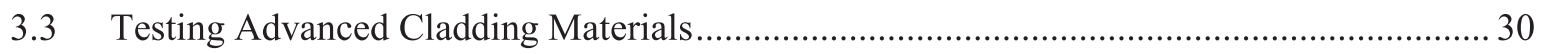

4. Breakout Session Summary: Advanced Nuclear Fuels ................................................................. 35

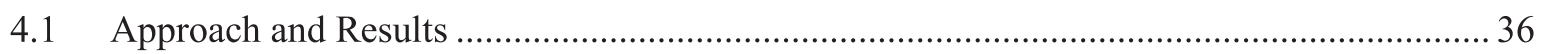

5. Breakout Session Summary: Operations/Safety Constraints........................................................ 42

5.1 Fuel Fabrication/Reactor Operation Metrics.................................................................. 44

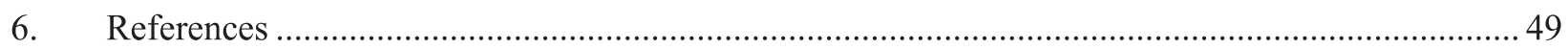

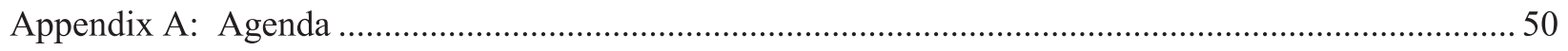

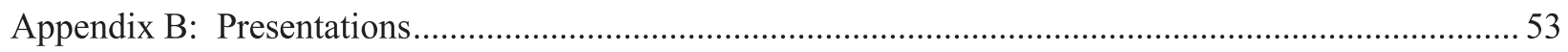

\section{FIGURES}

Figure 1. RD\&D Strategy for Enhanced Accident Tolerant Fuel Development .................................... 12

Figure 2. Integrated Approach for Fuel Cycle Technologies.............................................................. 13

Figure 3. Major issues that need to be addressed in establishing accident tolerant fuel attributes............ 14

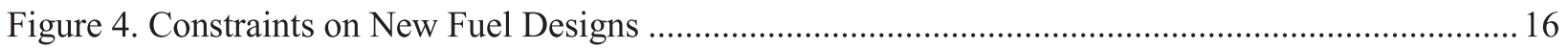


Figure 5. Operating Conditions Categories for Safety Evaluation of Nuclear Power Plants

Figure 6. LWR severe accident-relevant melting and chemical interaction temperatures which result in the formation of liquid phases [Reference: P. Hoffman, J. Nuc. Mat. 270 (1999) 194-211].

Figure 7. A diagram that describes an approach to assessing the enhanced accident attributes of a proposed fuel design.

\section{TABLES}

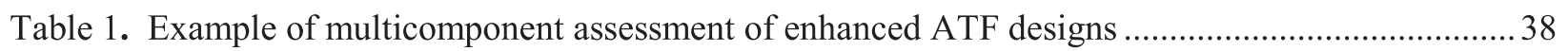

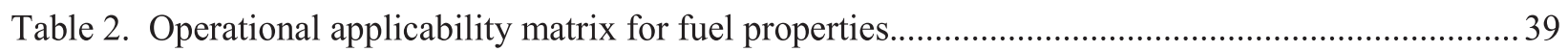

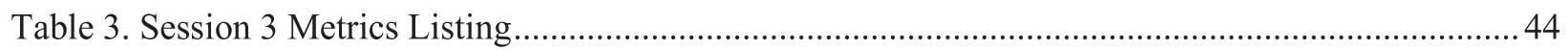




\section{ACRONYMS}

AFC

ANL

$\mathrm{AOO}$

ATR

ATWS

BDBA

BWR

$\mathrm{CD}$

CFR

CTE

DBA

DNB

DOE-NE

ECCS

DOE-EM

FCCI

FCMI

FCRD

FMEA

FOA

FY

HFIR

IASCC

INL

IRP

LBLOCA

LOCA

LTA
Advanced Fuels Campaign

Argonne National Laboratory

Anticipated Operational Occurrences

Advanced Test Reactor

anticipated transients without scram

beyond design basis accidents

Boiling Water Reactor

Critical Decision

Code of Federal Regulations

coefficient of thermal expansion

design-basis accident

departure from nucleate boiling

U.S. Department of Energy Office of Nuclear Energy

emergency core cooling system

DOE-Office of Environmental Management

fuel clad chemical interaction

fuel clad mechanical interaction

Fuel Cycle Research and Development

Failure Modes and Effects Analysis

Funding Opportunity Announcement

fiscal year

High Flux Isotope Reactor

irradiation assisted stress corrosion cracking

Idaho National Laboratory

Integrated Research Project

large break LOCA

loss-of-coolant accident

lead test assembly 
LTR lead test rod

LWR light water reactor

NDE non-destructive examination

NEA Nuclear Energy Agency (OECD)

NNSA National Nuclear Security Administration

NRC Nuclear Regulatory Commission

NSC nuclear science committee

OECD Organization for Economic Cooperation and Development

ORNL Oak Ridge National Laboratory

PIE postirradiation examination

ppm parts per million

PWR pressurized water reactor

R\&D research and development

RD\&D research, development, and demonstration

RIA reactivity insertion accident

SBLOCA small break LOCA

SSC systems, structures, and components

TREAT Transient Reactor Experiment and Test Facility

$\mathrm{UO}_{2} \quad$ uranium oxide 


\section{ENHANCED ACCIDENT TOLERANT LWR FUELS NATIONAL METRICS WORKSHOP}

\section{Introduction}

The U.S. Department of Energy Office of Nuclear Energy (DOE-NE), in collaboration with the nuclear industry, has been conducting research and development (R\&D) activities on advanced Light Water Reactor (LWR) fuels for the last few years. The emphasis for these activities was on improving the fuel performance in terms of increased burnup for waste minimization and increased power density for power upgrades, as well as collaborating with industry on fuel reliability.

After the Fukushima events in March 2011, the emphasis in DOE-NE R\&D and industrial activities has shifted the focus of advanced fuel development to accident performance under extended loss of active cooling and steam exposure (e.g., Fukushima scenario). Subsequently, the Congressional appropriation language for FY 2012 included specific language for DOE-NE to initiate an aggressive RD\&D program for LWR fuels with enhanced accident tolerance.

The DOE Fuel Cycle Research and Development (FCRD) Advanced Fuels Campaign (AFC) was reorganized at the beginning of FY-13 to include research, development, and demonstration (RD\&D) on Accident Tolerant Fuels (ATF). This mission emphasizes the development of novel fuel and cladding concepts to replace the current zirconium alloyuranium dioxide $\left(\mathrm{UO}_{2}\right)$ fuel system. The initial effort will focus on applications in operating reactors or reactors with design certifications. The goal is to insert a lead test assembly (LTA) or lead test rod (LTR) into a commercial reactor within ten years (i.e. by 2022).

Fuels with enhanced accident tolerance are those that, in comparison with the standard $\mathrm{UO}_{2}$-zirconium alloy system currently used by the nuclear industry, can tolerate loss of active cooling in the reactor core for a considerably longer time period (depending on the LWR system and accident scenario) while maintaining or improving the fuel performance during normal operations, and operational transients, as well as design-basis and beyond design-basis events.

The overall draft strategy for development and demonstration is comprised of three phases: Feasibility Assessment and Downselection; Development and Qualification; and Commercialization. The activities performed during the feasibility assessment phase include laboratory scale experiments; fuel performance code updates; and analytical assessment of economic, operational,

MISSION

Develop advanced fuels/cladding and non-design intrusive reactor system technologies (e.g. instruments, auxiliary power sources) with improved performance, reliability and safety characteristics during normal operations and accident conditions, while minimizing waste generation. safety, fuel cycle, and environmental impacts of the new concepts. The development and qualification stage will consist of fuel fabrication and large scale irradiation and safety basis testing, leading to qualification and ultimate Nuclear Regulatory Commission (NRC) licensing of the new fuel. The commercialization phase initiates technology transfer to industry for implementation. 


\subsection{Challenges in Developing Accident Tolerant Fuel}

The scientific and engineering challenges associated with nuclear technology result in a long, complicated fuel qualification process. Figure 1 illustrates the three phased approach leading to commercialization. Phase 1 includes feasibility assessment and down-selection. Fuel concepts will be developed, tested, and evaluated. Feasibility assessments (laboratory scale experiments; fuel performance code updates; and analytical assessment of economic, operational, safety, fuel cycle, and environmental impacts) of the new concepts will be done to downselect concepts for further development. In Phase 2, the fabrication process will expand to industrial scale for lead test assemblies (LTA) and lead test rods (LTRs). Finally, Phase 3 establishes the commercial fabrication capabilities.

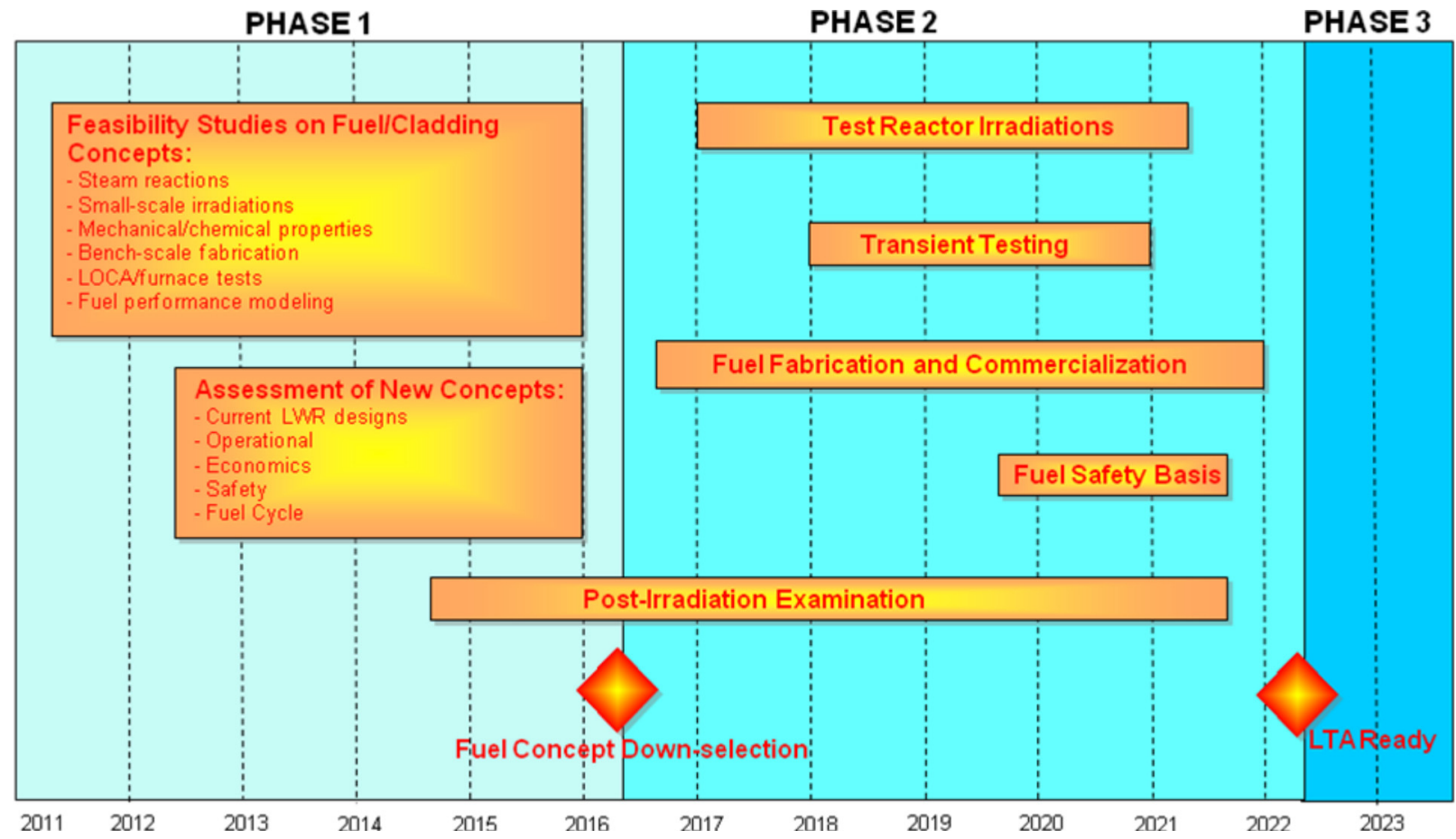

Figure 1. RD\&D Strategy for Enhanced Accident Tolerant Fuel Development

The RD\&D strategy adopts an aggressive development schedule subject to annual funding cycles and national laboratory facility constraints. Additional challenges include the need to fully define "Enhanced Accident Tolerance" along with testing and qualification requirements. The attributes are not equal in importance, requiring prioritization to determine which attributes to test and what metrics are needed to evaluate attribute compliance. Finally, accident tolerance cannot solely be the development responsibility of the Advanced Fuels Campaign program. Accident tolerance is ultimately a nuclear plant issue and advanced, accident tolerant fuels must be embraced by industry.

Newly developed advanced nuclear fuels must be capable of integration into the nuclear fuel cycle system (Figure 2) to ultimately be accepted by utilities and vendors. The challenge is to get the best performance at each step, and to understand how it affects other parts of the system. Overall, the objective is to develop a sustainable fuel cycle in the long run, with near-term applications (possibly in support of EM and the National Nuclear Security Administration (NNSA)). 
Front End

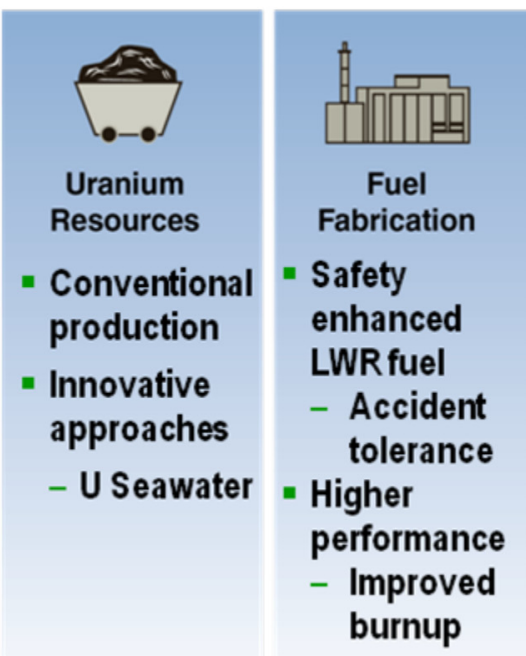

Back End

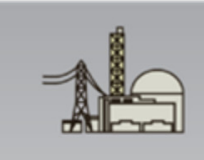

Reactors

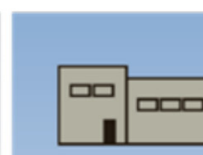

Interim

Storage

- Evaluating

extended

time frames

- Transport

after storage

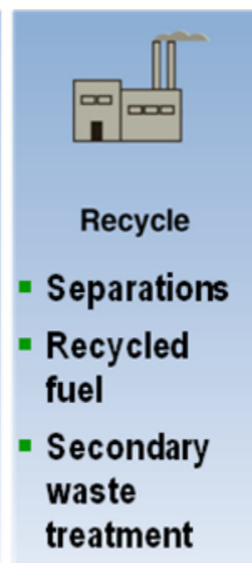

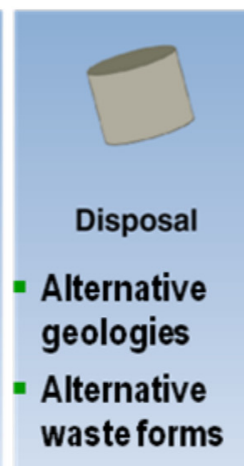

waste forms

Figure 2. Integrated Approach for Fuel Cycle Technologies

DOE relies on an integrated R\&D strategy that includes national laboratories, universities, nuclear industry, utilities, and the international community. Successful ATF development will require close collaboration between these organizations to overcome the significant schedule, funding, and technical challenges.

\subsection{Attributes for Enhanced ATF}

To mitigate or reduce the consequences of fuel failure due to steam exposure at elevated temperatures, the attributes identified in the following subsections will be considered. They provide qualitative guidance for parameters that will be considered for fuels with enhanced accident tolerance. It may be unnecessary to improve in all attributes and it is likely that some attributes or combination of attributes provide meaningful gains in accident tolerance, while others may provide only marginal benefits. It should be noted that in some cases, the described consequences of accident conditions (e.g. hydrogen generation) may be specific to the current zirconium alloy $\mathrm{UO}_{2}$ fuel system. Other fuel / cladding systems could present

Enhanced Accident Tolerant Fuels Can tolerate loss of active cooling in the reactor core for a considerably longer time period, while maintaining or improving the fuel performance during normal operations, operational transients, as well as design-basis and beyond designbasis events. additional effects not expressed here (e.g. generation of $\mathrm{CO}$ ) that must be considered in evaluation of the proposed system. A brief description of the desired attributes is provided in this section and summarized in Figure 3. 


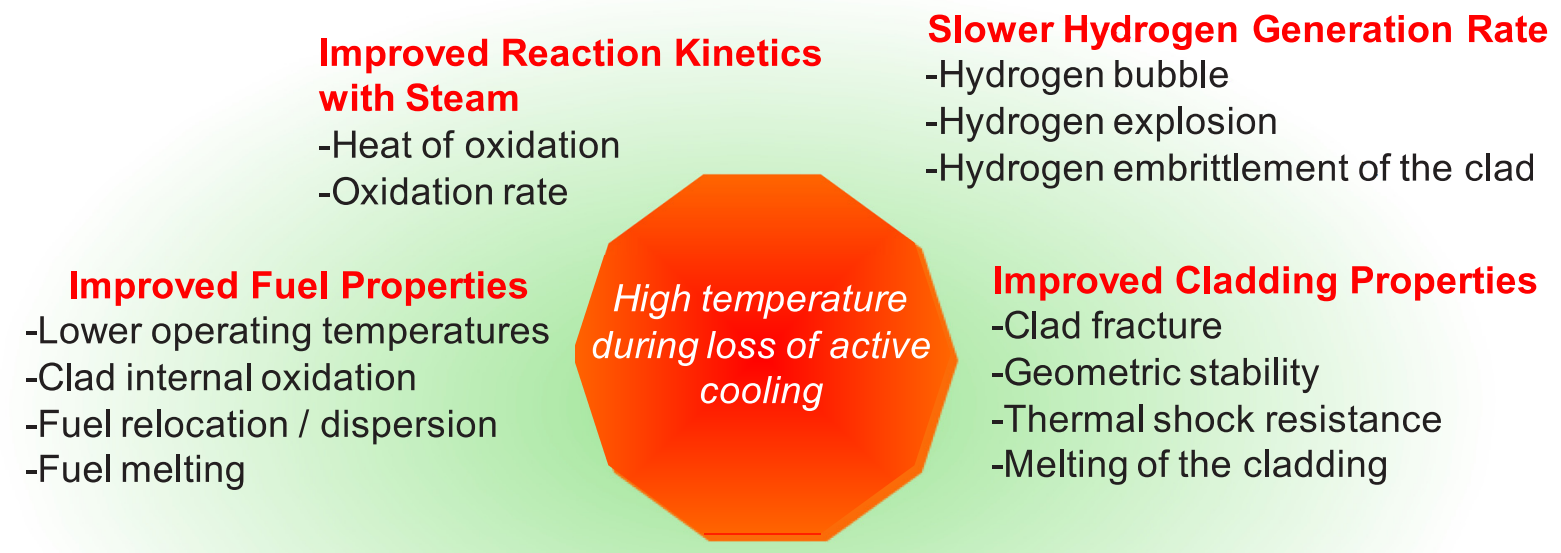

\section{Enhanced Retention of Fission Products \\ -Gaseous fission products \\ -Solid/liquid fission products}

Based on these safety-related issues, metrics for quantifying the enhancements in accident tolerance must be developed in conjunction with the safety features of a given LWR design and based on specific accident scenarios.

Figure 3. Major issues that need to be addressed in establishing accident tolerant fuel attributes.

\section{Hydrogen Generation Rate}

Hydrogen buildup in the reactor vessel can lead to energetic explosions as seen in the Fukushima events. Under a high-temperature steam environment, it is not possible to totally avoid hydrogen generation. Rapid oxidation of standard zirconium alloy cladding results in free hydrogen generation. This exothermic reaction increases the cladding temperature, which further accelerates free hydrogen generation. A related issue is the diffusion of free hydrogen into the unoxidized portion of the cladding, resulting in enhanced embrittlement and potential cladding failure.

A desired alternative would be a cladding material that resists oxidation or reduces the rate of oxidation, therefore resulting in a slower free hydrogen generation rate. Materials with lower heat of oxidation may be important in limiting the temperatures during an accident. Materials that are less susceptible to hydrogen diffusion may address the rapid embrittlement issue.

\section{Fission Product Retention}

Cladding provides the initial barrier to release of fission products in nuclear fuel. Upon cladding failure, retention of the fission products within the vessel is required to minimize releases to the environment. This includes both gaseous and solid fission products. Due to the potential severity of fission product release to the environment, retention within the fuel is of the utmost importance. While total retention may not be possible, even partial retention (especially for highly mobile fission products) would be a substantial improvement.

The desired improvement would be to prevent melting or dispersion of the fuel by utilization of high temperature/strength cladding materials that would retain cladding integrity beyond the current limitations of zirconium alloy cladding. Additionally, fission product retention techniques or chemically linking the 
fission products in a fuel matrix may be options, as long as the concepts can tolerate high temperatures. Building additional barriers around the fuel to contain fission products (as a backup to containment provided by the cladding) also may be envisioned.

\section{Cladding Reaction with Steam}

When cladding is exposed to steam at high temperature, multiple issues need to be considered. As previously stated, the high temperature steam interaction with zirconium alloy fuel cladding causes an exothermic oxidation reaction and resulting hydrogen generation. In addition, this reaction deteriorates the structural integrity of the cladding which could result in fission product release into the reactor vessel.

Advanced cladding materials should demonstrate enhanced tolerance to radiation and oxidation under high-temperature exposure while specifically considering mechanical strength and structural integrity at the end of life and when exposed to high-temperature steam for an extended duration.

\section{Fuel Cladding Interactions}

In the event of cladding failure, fuel behavior is important. The issues are fuel melting and relocation, as well as fuel dispersion into the coolant. Fuel cladding chemical interactions (FCCIs), fuel cladding mechanical interactions (FCMIs) and fuel heating are important properties that must be understood during normal operation and accident conditions.

The design option would be to develop fuels with reduced FCCI and FCMI, and with lower operating temperatures relative to the zirconium alloy $-\mathrm{UO}_{2}$ system. Higher melting point and structural integrity at high temperatures (i.e. less dispersive) are also desired improvements.

\subsection{Constraints on Development of Enhanced ATF}

The current nuclear power industry is based on mature technology and has a stellar safety and operational record. Except for a few extremely rare events, the current $\mathrm{UO}_{2}$-zirconium alloy fuel system meets all performance and safety requirements while keeping nuclear energy an economically competitive cleanenergy alternative for the United States. Any new fuel concept proposed for enhanced accident tolerance under rare events should be compliant with and evaluated against current design, operational, economic, and safety requirements. Fuel cycle considerations must also be considered, especially for concepts that represent a significant departure from the current technology. A brief summary of the constraints is provided below and summarized in Figure 4. 


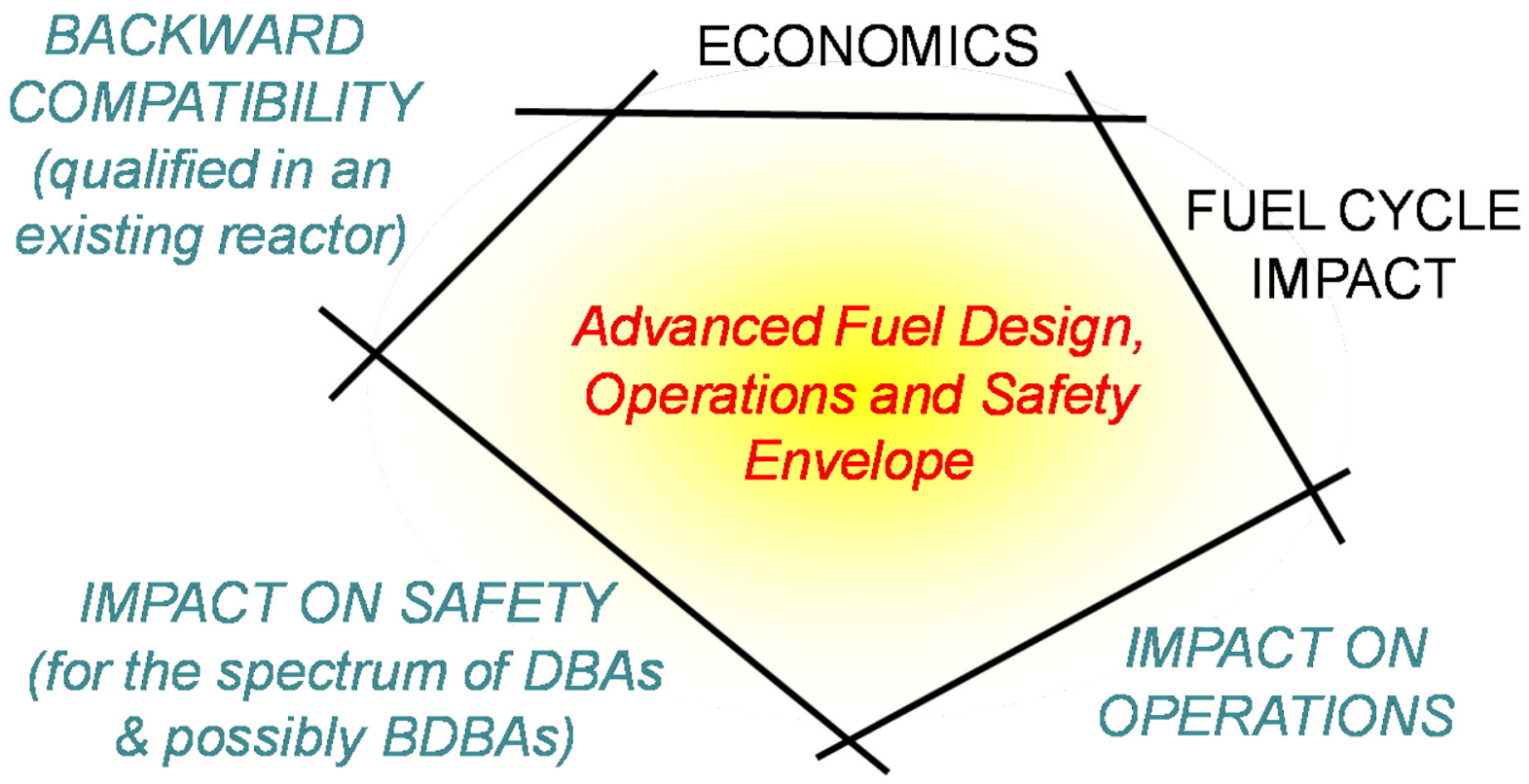

Figure 4. Constraints on New Fuel Designs

\subsubsection{Current LWR Designs}

In order to meet the desired development timeline, advanced fuel and/or cladding concepts developed under this initiative must be suitable for use in existing LWRs or reactor concepts with design certifications (GEN-III+). Longer term concepts may be considered in conjunction with the near-term focus as resources permit. Regardless of whether the actual deployment target is a current or future reactor, the fuel is highly likely to be qualified and demonstrated in existing commercial reactors. Proposed fuel concepts should not require plant modifications to the host reactor for demonstration irradiation of the concept and should further be as near to prototypical as possible.

\subsubsection{Operational Considerations}

Before introducing a new fuel into an existing, or planned, reactor system, plant operations must be considered. The new fuel system must maintain or extend plant operating cycles, reactor power output, and reactor control. Reducing the availability or power output would be disruptive to utilities; who would not readily accept this change unless the benefits outweigh the lost productivity. To maintain current operation, some of the fuel system concepts would require higher fuel enrichment. While the impact of higher enrichments is fairly well understood from a technical perspective, regulatory issues would have to be addressed.

\subsubsection{Economic Impacts}

After decades of development and optimization, the $\mathrm{UO}_{2}$-zirconium alloy fuel system is a streamlined technology that accounts for a relatively small percentage of the overall nuclear electricity production cost. Any proposed fuel system is unlikely to be able to compete economically with the current system; at least not initially. Fuels that require enrichment higher than that of current fuel (about 4 to $4.5 \%$ ) are especially likely to cost more because enrichment is a major cost contributor. Increased enrichment could 
additionally require modifications to fuel fabrication facilities. Therefore, it is important to carefully assess the economic impact of the new technology and to determine how much additional fuel cost the utilities will accept. As a potential solution, going to higher burnup (extended cycle with reduced waste and reduced refueling cost) and to higher power densities (power upgrades) could mitigate some of the impact. While focusing on enhanced safety it is necessary to maintain enhanced performance goals as an economic consideration.

\subsubsection{Safety Envelope}

Performance of a new fuel system will be compared to the performance of the $\mathrm{UO}_{2}$-zirconium alloy system to assess its accident tolerance. However, operational transients and design-basis accidents must be considered in evaluating the new fuel system. Specific emphasis on long-term station blackout, loss-ofcoolant accidents (LOCAs), and reactivity insertion accidents (RIA) will be made. Fuel performance during anticipated transients without scram must also be evaluated and must be shown to be similar to or better than the current system.

For design-basis LOCAs, the U.S. Nuclear Regulatory Commission (NRC) is currently in the process of evaluating the safety envelope for high-burnup fuels (about 50 Giga-Watt-days/metric ton). Because some of the issues are similar to those that need to be addressed by the new fuel system, this is an opportunity to closely work with NRC on assessment methodologies.

\subsubsection{Fuel Cycle Impacts}

The impact of new fuels and cladding on the front-end of the nuclear fuel cycle must be carefully assessed within the framework of current and future regulations and policies. Some of the fuel systems that will be considered require higher fuel enrichment. For instance, if an advanced stainless steel cladding replaces zirconium-based alloys, the enrichment required would increase by 1 to $2 \%$. On the other hand, the very robust fuel forms with multiple layers of containment and fission-product barrier (e.g. microencapsulated fuels) would require enrichment up to the low-enrichment limit of $<20 \%$. In addition to the economic penalty, higher enrichments would result in lower uranium utilization and would have a major impact on the current enrichment and fuel fabrication plants.

A new fuel system could also have an impact on the back-end of the fuel cycle. The storage (wet and dry) and repository performance of the fuel (assuming a once-through fuel cycle) must not be degraded; otherwise, engineering solutions must be augmented during storage and disposal. Over the long term, U.S. policy changes to transition to a closed fuel cycle with reprocessing and recycling would require evaluation of the impact of the new fuel form on reprocessing.

\subsection{NRC Guidance on Reactor Operating Condition Definitions}

Figure 5 provides an overview of the NRC guidance for categorizing the operating conditions in evaluating the performance of the reactor and fuel system to meet the requirements for performance and safety. The more recent NUREG-0800 Rev. 3 event categorization approach defines conditions of normal operation as those that are expected to occur once or more during the lifetime of the plant, sometimes called Anticipated Operational Occurrences (AOOs). On the other hand, Postulated Accidents are unanticipated occurrences that can have consequences of significant radioactivity release that must be within off-site dose limits. In addition to categorizing the reactor conditions by event frequency, reactor 
conditions are also classified by type of event, that is, by the effect on the plant. Beyond normal operation, the types of reactor events are generally grouped into seven categories:

- Increase in heat removal by the secondary system (e.g. increase in feedwater flow)

- Decrease in heat removal by the secondary system (e.g. loss of external load)

- Decrease in reactor coolant system flow rate (e.g. seized pump shaft accident)

- Reactivity and power distribution anomalies (e.g. control rod ejection accident)

- Increase in reactor coolant inventory (e.g. inadvertent emergency core cooling system [ECCS] actuation)

- Decrease in reactor coolant inventory (e.g. loss of coolant accident [LOCA])

- Radioactive release from a subsystem or component (e.g. steam generator tube rupture)

\begin{tabular}{|l|l|l|}
\hline $\begin{array}{l}\text { ANSI N18.2/ANS 51.1/52.1 } \\
\text { Event Categorization }\end{array}$ & \multicolumn{1}{|c|}{$\begin{array}{c}\text { NUREG-0800 Rev. 3 } \\
\text { Event Categorization }\end{array}$} & \multicolumn{1}{c|}{ Example Events } \\
\hline $\begin{array}{l}\text { Category I - Normal Operation and } \\
\text { Operational Transients }\end{array}$ & $\begin{array}{l}\text { Normal Operation and Anticipated } \\
\text { Operational Occurrences (AOOs) } \\
\text { (Events expected to occur once or } \\
\text { more per reactor lifetime) }\end{array}$ & $\begin{array}{l}\text { ・ Increase in feedwater flow } \\
\text { - Loss of feedwater heater } \\
\text { - Loss of external load }\end{array}$ \\
\hline $\begin{array}{l}\text { Category II - Moderate Frequency } \\
\text { (once per calendar year) }\end{array}$ & $\begin{array}{l}\text { - RCCA withdrawal at power } \\
\text { Category III - Infrequent Incidents } \\
\text { (once per reactor lifetime) }\end{array}$ & $\begin{array}{l}\text { - Complete loss of forced reactor flow } \\
\text { - Reactor Coolant Pump Shaft } \\
\text { Break/Seizure }\end{array}$ \\
\hline $\begin{array}{l}\text { Category IV - Limiting Faults (not } \\
\text { expected to occur - consequences } \\
\text { of significant radioactive release) }\end{array}$ & $\begin{array}{l}\text { Postulated Accidents (not expected } \\
\text { to occur - consequences of } \\
\text { significant radioactive release) }\end{array}$ & $\begin{array}{l}\text { - Control Rod Ejection } \\
\text { - Control Rod Drop }\end{array}$ \\
\hline
\end{tabular}

Figure 5. Operating Conditions Categories for Safety Evaluation of Nuclear Power Plants

The operating conditions listed in Figure 5 are used in the design of the reactor systems, structures, and components (SSCs) critical to safety. The events in the figure are generally called the design basis conditions and the accidents are referred to as design basis accidents (DBAs). Acceptance criteria to ensure successful operation of the SSCs are defined and safety analyses are used to demonstrate compliance with these criteria. Situations in which key SSCs are inoperable are called severe accidents, falling outside the design basis, or sometimes referred to as beyond design basis accidents (BDBAs) condition. Severe accidents generally lead to significant core damage, high temperature conditions leading to chemical reactions and generation of hydrogen and the release of radioactive fission products into the containment. While not normally included in the design of the reactor or fuel systems, severe accident conditions are an important element in the review effort performed to identify metrics for enhanced accident tolerant fuel.

The impact of different material properties and fuel behaviors on the important characteristics or attributes of fuel performance was evaluated using seven different accident/AOO conditions (see Section 4), including two severe accident conditions (with and without quench), two postulated accidents (LOCA, reactivity initiated accident (RIA)), two AOOs (loss of coolant flow and reactor overpower) and normal operation. These seven scenarios were selected to provide the spectrum of initial and boundary conditions defined by the reactor/fuel power level, coolant flow rate, temperature, and pressure, and 
duration of the event that fuel would be expected to endure. The thermal, mechanical, and chemical stability attributes of the fuel must be considered throughout the entire spectrum of conditions, not just select state points (i.e. maximum temperature) because of the complex relationships between the properties and these attributes.

A short description of each type of operating/accident environment is given below.

\subsubsection{Normal Operation}

Normal operation spans the conditions from beginning of life to fuel discharge. The power conditions during normal operation include reactor startup at the beginning of each cycle, mid-cycle power maneuvers, and restart from unplanned outages. Coolant chemistry conditions needed to maintain reactivity control, corrosion control of other components in the primary system, and impurities from leaching from piping can have an impact on the cladding surface. Fuel burnup levels required to meet current operating strategies are in the 50 to $60 \mathrm{GWd} / \mathrm{tU}$ range. Resident times for the fuel range from 4 to 6 years.

\subsubsection{Overpower Anticipated Operation Occurrence}

The overpower AOO is a moderate frequency event that occurs by a number of initiating conditions, such as loss of feedwater heater, uncontrolled control rod withdrawal at power, etc. The power increase during this event leads to an increase in fuel temperatures, fuel thermal expansion strain, and cladding heat flux to the coolant. The event is terminated by a reactor scram on a high power signal. The fuel performance behaviors of interest during this event are the power to melt ratio for the fuel, the cladding fracture strain and the potential for stress corrosion cracking by fission products. Furthermore, the increase in cladding heat flux reduces the margin to DNB.

\subsubsection{Decrease in Coolant Flow Anticipated Operation Occurrence}

The decrease in coolant flow AOO is a moderate frequency event when initiated from a reactor pump trip and as a postulated accident in the case of a seized pump rotor or pump shaft breakage. The decrease in coolant flow reduces the cladding to coolant heat transfer conditions, with a corresponding decline in the margin to DNB. The fuel performance behavior of interest during this event is the potential for post-DNB heat transfer conditions. Such conditions cause a significant increase in cladding temperature, increased reaction with the coolant water, and cladding collapse. Rewetting of the cladding by either reduction in power (scram) or increase in flow can result in thermal shock loads due to quench.

\subsubsection{Reactivity Initiated Accident (RIA) Design Basis Accident}

A control rod ejection event in a PWR or a control rod drop event in a BWR are postulated reactivity initiated accidents that can lead to prompt reactivity insertion and rapid increase in reactor power to many times $100 \%$ rated power. This design basis accident is used to determine the impact of excess reactivity within the core on the reactivity worth of a single control rod. The rapid insertion of reactivity during this event causes power pulses that have widths ranging from 10 to 50 milliseconds. These conditions produce near-adiabatic heat up of the fuel material for most of the energy deposition phase. Heat conduction from the fuel to the coolant begins during later portions of the power pulse or after the power pulse is completed. As a result, the performance of the fuel during a RIA event can generally be viewed as having two phases, a near-adiabatic heat up phase during the first 10-50 ms (Phase 1) and a heat transfer phase lasting from 10 to several hundred seconds (Phase 2). 
Phase 1 is characterized by the density, heat capacity, conductivity, and thermal expansion of the fuel material and the cladding ductility at operating temperature. The stored energy capacity of the fuel influences the fuel enthalpy and temperature rise during the rapid energy deposition that occurs in Phase 1. During the rapid energy deposition, the temperature profile in the pellet follows the radial power profile, which is flat for lower burnup fuel and peaked at the pellet surface for higher burnup fuel. At large energy depositions, the rapid heat up of the fuel pellet can cause melting and fragmentation of the pellet, and, potentially, melting of the cladding. The increase in fuel enthalpy causes pellet thermal expansion, and depending on the pellet-cladding gap size, mechanical strain on the cladding. The ability of the cladding to accommodate the pellet thermal expansion strain is defined by the material ductility. The fuel thermal expansion stabilizes once heat conduction to the cladding and coolant begins.

Heat-up of the cladding is the start of Phase 2. This phase is controlled by the high temperature mechanical and chemical response of the cladding. For large energy depositions, departure from nuclear boiling (DNB) is likely with a significant drop in the cladding-to-coolant heat transfer and a corresponding increase in cladding surface temperature. After a short period of post-DNB heat transfer conditions, rewetting of the cladding will occur, producing thermal shock quench stresses in the cladding. Depending on the cladding embrittlement level, fracture of the cladding is possible.

\subsubsection{Loss of Coolant Accident (LOCA) Design Basis Accident}

The LOCA event is a postulated accident that spans a range of primary system pipe breaks leading to a reduction in the coolant inventory. There are two main LOCA events: the large break LOCA (LBLOCA) and the small break LOCA (SBLOCA). The LBLOCA considers a rupture of a major coolant pipe that result in a rapid depressurization of the primary coolant system and uncovering of the reactor core. The LBLOCA causes an increase in the cladding temperature that is controlled by the stored energy of the reactor at the initial blowdown and by the decay heat during the reflood phase. Scram of the reactor during the depressurization shuts down the energy generation rate from fission at the initiation of the event. At some point, the emergency core cooling system (ECCS) actuates to provide coolant makeup and reflood the core.

The response of the fuel in the core during a LBLOCA is used to size and time the actuation of the ECCS to ensure compliance with the fuel damage limits specified in Title 10 of the Code of Federal Regulations Part 50.46b. The fuel and cladding experience several important thermal, mechanical, and chemical processes during a LBLOCA. These include rapid heating to temperatures in excess of $800^{\circ} \mathrm{C}$ during the blowdown phase. For zirconium alloy cladding, the fuel rod pressure exceeds the coolant pressure and rapid thermal creep/plasticity leads to ballooning and burst of the cladding between 700 and $800^{\circ} \mathrm{C}$. Prior to core reflood by the ECCS, the decay heat combined with the steam heat transfer conditions causes the fuel rod to continue to heat up, with cladding temperatures reaching between $1000^{\circ} \mathrm{C}$ and $1200^{\circ} \mathrm{C}$ for worst-case assumptions. During this high temperature period, the steam reacts with the zirconium-alloy cladding, oxidizing the outer surface and generating hydrogen. Rapid thermal quench occurs between 5 and 10 minutes after the oxidation process starts. The quench process produces thermal shock loads that can cause cladding fracture depending on the level of embrittlement from oxygen uptake.

In the case of a SBLOCA, the size of the pipe break limits the depressurization event. The loss of coolant inventory occurs at a slower rate, but the core can still become uncovered, leading to increased fuel rod temperatures. The anticipated temperature excursion in a SBLOCA generally remains below that of a LBLOCA, but the time at elevated temperature is considerably longer. A SBLOCA can last between 30 and 60 minutes before the ECCS system terminates the event. 


\subsubsection{Severe Accidents (with and without quench)}

Severe accident conditions include temperature, time, and coolant conditions well above those considered in design basis accidents. The maximum allowable cladding temperature during a LOCA event is 1200 ${ }^{\circ} \mathrm{C}$ and the fuel material temperature remains well below melting due to appropriate actuation of the emergency core cooling system (ECCS). Severe accidents, where heat removal capabilities are insufficient to remove the decay heat, can result in cladding temperatures that exceed $1200^{\circ} \mathrm{C}$, the formation of eutectics between the fuel, cladding, control rod and structural material that can reduce melting temperatures, and extended duration of poor heat removal conditions for long periods of time $(>8$ $\mathrm{hrs}$ ). Severe accident response could include core reflood with coolant, leading to quench (thermal shock loads), and no reflood (long times at elevated temperature).

\section{Metrics Workshop Overview}

The attributes for fuel systems with enhanced accident tolerance provide qualitative guidance for parameters that must be considered in the development of such fuels. However, quantitative metrics associated with these attributes must also be developed. To initiate the development of quantitative metrics to quantify success, a Light Water Reactor Enhanced Accident Tolerant Fuels Metrics Development Workshop was held October 10-11, 2012, in Germantown, Maryland.

The purpose of the workshop was to begin defining requirements for down-selection among options during the feasibility assessment. This process includes identifying the important attributes and operational and safety constraints for ATF. Quantitative metrics will then need to be defined to evaluate various candidate technologies through testing and analysis.

To initiate this process, breakout sessions were organized around three attribute and constraints sets:

1. Improved Nuclear Fuel Cladding - Improved Reaction Kinetics with Steam/Slower Hydrogen Generation Rate/Cladding Thermo-Mechanical Properties

2. Advanced Nuclear Fuel - Improved Fuel and Cladding Thermo-Mechanical Properties, including Fission Product Retention

3. Constraints - Current LWR Designs/Operational and Safety Envelope/Economic Impacts/ Definition of Representative Accident Scenario.

The nuclear fuel and cladding sessions were instructed to:

- Define critical attributes: properties, performance characteristics

- Map the merit of the attributes against potential operational or safety envelope benefits

- Quantify the target value for the attribute/property, if possible

- Define required analyses (accident scenarios) to quantify the target value.

The operations and safety constraints session was instructed to:

- Identify potential assembly design changes within the design constraints

- Identify the accident scenarios to be considered to begin defining the safety envelope (identification of limiting components beyond the fuel assemblies)

- Define the operations envelope based on margins required during transients (initial conditions for accident scenarios)

The output from each breakout session is provided in the following sections. While the breakout discussions did not fully quantify the desirable attributes for accident tolerance, significant progress was 
made toward qualitative identification of desirable properties and performance, while noting potential challenges associated with achieving that performance. In identifying acceptable cladding properties and analyzing options, one must consider the integral fuel and reactor system. While separate breakout discussions were held to develop initial metrics guidelines, a comprehensive view should be taken with regard to meeting the established accident tolerant attributes.

The qualitative metrics guidelines generated during the national workshop will be further developed following the International LWR Fuels Metrics Workshop in December 2012 to incorporate input from the international community. Refinement of the ATF metrics will be accomplished via interactive discussion among the original workshop participants to further clarify quantitative values for key performance parameters and goals. Both qualitative and quantitative metrics will be used as a measure for the various ATF concepts being investigated by industry, academia and the national laboratories to rank their potential performance in a commercial reactor application. In this manner the number of ATF options to be tested as a lead test rod or assembly in a commercial reactor will be reduced to a manageable number following significant nonnuclear characterization and test reactor irradiation.

\subsection{ATF Metrics Development}

The Organization for Economic Cooperation and Development (OECD) Nuclear Energy Agency (NEA) Workshop on Accident Tolerant Fuels of LWRs will be held in December 2012 in NEA headquarters in Paris, France. The main objectives of this international workshop are to review lessons learned from the Fukushima accident and identify desired advanced fuel characteristics; evaluate state-of-art of potential fuel/cladding candidates and related technical and regulatory issues; and discuss future programs of work and international co-operations. Technical sessions will be held on "Accident tolerant fuel design" and "Reactor operation, safety, fuel cycle constraints, economics, and licensing" will be organized. Results of the international workshop will be used in conjunction with the national workshop results in establishing standard metrics for all accident tolerant fuel concepts currently under development.

The national workshop agenda is provided in Appendix A and presentations made during the opening session are provided in the subsequent Appendices. Individual participants in each breakout are also noted.

The input gathered during the two metrics meetings will be reviewed by AFC. The attributes and common analysis platforms will be used to develop a set of metrics to assess the ATF concepts. This will provide a common assessment of the success or failure of ATF technologies. 


\section{Breakout Session Summary: Advanced Nuclear Fuel Cladding}

Attribute Set: Improved reaction kinetics with steam, slower hydrogen generation rate, and cladding thermo-mechanical properties.

Participants:

\author{
Shannon Bragg-Sitton, INL (Session Lead) \\ Mike Billone, ANL \\ Evan Dolley, GE-GRC \\ Juan Flores-Preciado, GE-GRC \\ Brent Heuser, U of Illinois \\ Rich Kochendarfer, AREVA
}

\author{
Stuart Maloy, LANL \\ Tarik Saleh, LANL \\ Kurt Sickafus, U of Tennessee - Knoxville \\ Lance Snead, ORNL \\ Kurt Terrani, ORNL \\ Ken Yueh, EPRI
}

While this group focused on attributes of advanced cladding materials and interaction of the cladding with the outside environment (e.g. cooling water under nominal conditions or steam under accident conditions), it was noted that the fuel / cladding system should be considered as a whole to ensure that the selections are mechanically, chemically, and neutronically compatible. Brainstorming discussions were organized as follows:

(1) Establish a common baseline.

a. Define key parameters for current Zr-based alloy cladding - normal operation.

b. Define key accident performance parameters for current Zr-based alloy cladding.

(2) Discuss attributes for advanced cladding options.

a. What parameters should be adjusted for enhanced accident tolerant cladding?

(3) Identify key measurements, parametric studies, and tests to measure key attributes.

a. Identify sensitivity analyses to be performed to highlight the most impactful properties/attributes.

b. Establish the testing envelope for each "class" of advanced cladding option (e.g. metallic, ceramic, and hybrid).

c. Develop a summary list of necessary test facilities; compare facility needs with current facility capabilities.

\subsection{Establish a Common Baseline}

At the start of the discussion it became evident that establishing a common understanding of the current state-of-the-art cladding design constraints and performance parameters would provide a useful starting point for determining how the existing Zr-based cladding options used in PWRs and BWRs might be improved. Key characteristics and performance criteria were identified, with quantitative values assigned where possible, both for normal operation and performance under off-normal events.

Normal Operating Parameters, Zr-based Cladding: 
- Fission product retention: $\sim 10^{-6}$ pin failure rate

- Radiation tolerant: up to $\sim 10 \mathrm{dpa}, 10^{22} \mathrm{n} / \mathrm{cm}^{2}$ fast $(>1 \mathrm{MeV})$

- Dimensional stability: Max 1\% axial elongation

- Cladding dimensions - 9-11 mm outer diameter, 0.6-0.7 mm wall thickness

- Thermal conductivity: $\sim 17.4 \mathrm{~W} / \mathrm{m}-\mathrm{K}\left(300{ }^{\circ} \mathrm{C}\right)$

- Heat capacity: $293 \mathrm{~J} / \mathrm{kg}_{-}{ }^{\circ} \mathrm{C}$

- Heat transfer coefficients - coolant / clad coupling (note that this is really a reactor design issue, but it is included in the discussion of baseline clad performance for completeness)

- Coolant / cladding interaction: Corrosion performance

- Oxide growth $\$ 100 \mu \mathrm{m}$, driven by concern for local spallation of the oxide leading to a cold spot in the cladding and excessive hydrogen migration to that cold spot; $\boldsymbol{\varsigma} 800$ wppm hydrogen (guideline; not regulated by NRC, but included in vendor technical specifications)

- Maximum limit on corrosion product buildup (linked to water chemistry specifications)

- Galvanic corrosion limits

- Requirement for all corrosion products to be benign with regard to other system components (e.g. corrosion products will not result in additional non-compatibility issues)

- Tritium release into coolant:

- While there is no established limit for tritium permeation, "low" permeation into the coolant is desirable. A reasonable limit may be $<10 \%$ of the total tritium generated within fuel rods permeating into the coolant.

- Note: $2000 \mathrm{Ci} / \mathrm{yr}$ tritium is generated within Zr-based fuel cladding due to ternary fissions and burnable poisons (e.g., $\mathrm{ZrB}_{2}$ ), which is greater than the tritium generated in the coolant due to boric acid additions to PWRs. Vendors assume that less than $2 \%$ of this tritium $(40 \mathrm{Ci} / \mathrm{y}$ ) permeates through $\mathrm{Zr}$-based alloy cladding to the coolant (for SS316 , the permeation could be as high as $90 \%$ ). A $10 \%$ limit would allow up to $200 \mathrm{Ci} / \mathrm{yr}$ added to the primary coolant.

- Hydrogen pick-up

- Peculiar to Zr-based alloys

- Varies with alloy from $100 \mathrm{ppm}$ to $800 \mathrm{ppm}$ (600 ppm should be acceptable under normal operating conditions

- Mechanical criteria

- Ductility: Currently 1\% min total elongation (below this is in the uncertainty margin)

- Note: New alloys are showing uniform elongation up to 5\%; total elongation up to $\sim 20 \%$. 
- Yield strength: current as-fabricated alloys, $\sim 150-400 \mathrm{MPa}$ at $340^{\circ} \mathrm{C}$ Ultimate tensile strength: $437 \mathrm{MPa}$ at room temperature (Zircaloy-4)

- Creep strain: $0.66 \%$ (Zircaloy-4); note that some cladding creep behavior is beneficial in fuel performance

- Resistance to crack propagation (fracture toughness)

- Fretting wear: $<10 \%$ of wall thickness

- Debris wear resistance

- Fabricable: weldable, thin-walled tube that maintains hermeticity

- Fuel-clad interaction behavior:

- Includes consideration of fission product interactions

- Current $\mathrm{Zr}$-alloy / $\mathrm{UO}_{2}$ system develops an oxide layer on the inside of the clad ( 10 micron)

- Burnup limit: Peak rod average - $62 \mathrm{MWd} / \mathrm{kg} \mathrm{U}$

Accident Performance, Zr-based Cladding:

The discussion of cladding performance under accident conditions first required definition of "baseline" design basis accidents (DBAs) and beyond design basis accidents (BDBAs). The current metric for fuel system performance during a DBA is that the cladding should maintain post-quench ductility by limiting the peak cladding temperature to $1204^{\circ} \mathrm{C}$ and the maximum oxidation level to $17 \%$ of the cladding wall thickness. It has been shown that the temperature and oxidation limits result in maintaining ductility for as-fabricated and very low burnup cladding. Changes underway in 10CFR50.46(b) and NRC Regulatory Guides will limit the oxidation level for DBAs based on pre-DBA hydrogen content (e.g., $4 \%$ for 600 wppm hydrogen). Under BDBA LOCA conditions, cladding will be subjected to higher temperatures and oxidation levels. Zr-based cladding alloys would experience longer times at increasing temperatures, higher oxidation rates, higher hydrogen release rates, and higher internal heat-of-oxidation rates. Accident scenarios considered by the breakout group are provided below.

Design Basis Accidents:

- Large Break Loss of Coolant Accident (LBLOCA) - double guillotine break of coolant line

- Small Break Loss of Coolant Accident (SBLOCA) - gradual loss of coolant over a longer period of time

- Reactivity Insertion Accident (RIA)

Beyond Design Basis Accidents:

- Short Term Station Blackout (immediate loss of power and water make-up)

- Long Term Station Blackout (loss of water make-up following battery exhaustion, loss of all power after 8 hours)

Several characteristics and performance parameters were discussed relative to the current state-of-the-art Zr-based cladding alloys. While not all of these parameters were assigned quantitative values during the breakout discussion, these values are available in existing databases. Key performance measures include 
coping time, behavior under elevated temperature conditions over long periods of time, and material oxidation. These measures are further defined below.

- Coping time under DBA and BDBA temperatures while maintaining coolable geometry; performance is highly dependent on operating time and hydrogen pickup. Current alloys provide the following performance:

- LBLOCA conditions: $<50$ to $300 \mathrm{sec}$ at $1204^{\circ} \mathrm{C}$

- SBLOCA: $\sim 1 \mathrm{hr}$ at $\leq 1050^{\circ} \mathrm{C}$

- Elevated temperature issues:

- Clad melt temperature $\sim 1760$ oC

- Temperatures for eutectic formation

- Eutectics may form at lower temperature and exhibit lower melting points (see Figure 6)

- Detrimental effect of eutectics on other components

- Runaway oxidation

- Occurs before the clad melt temperature is reached

- Relates to heat of oxidation and acceleration of the oxidation process as temperature further increases 


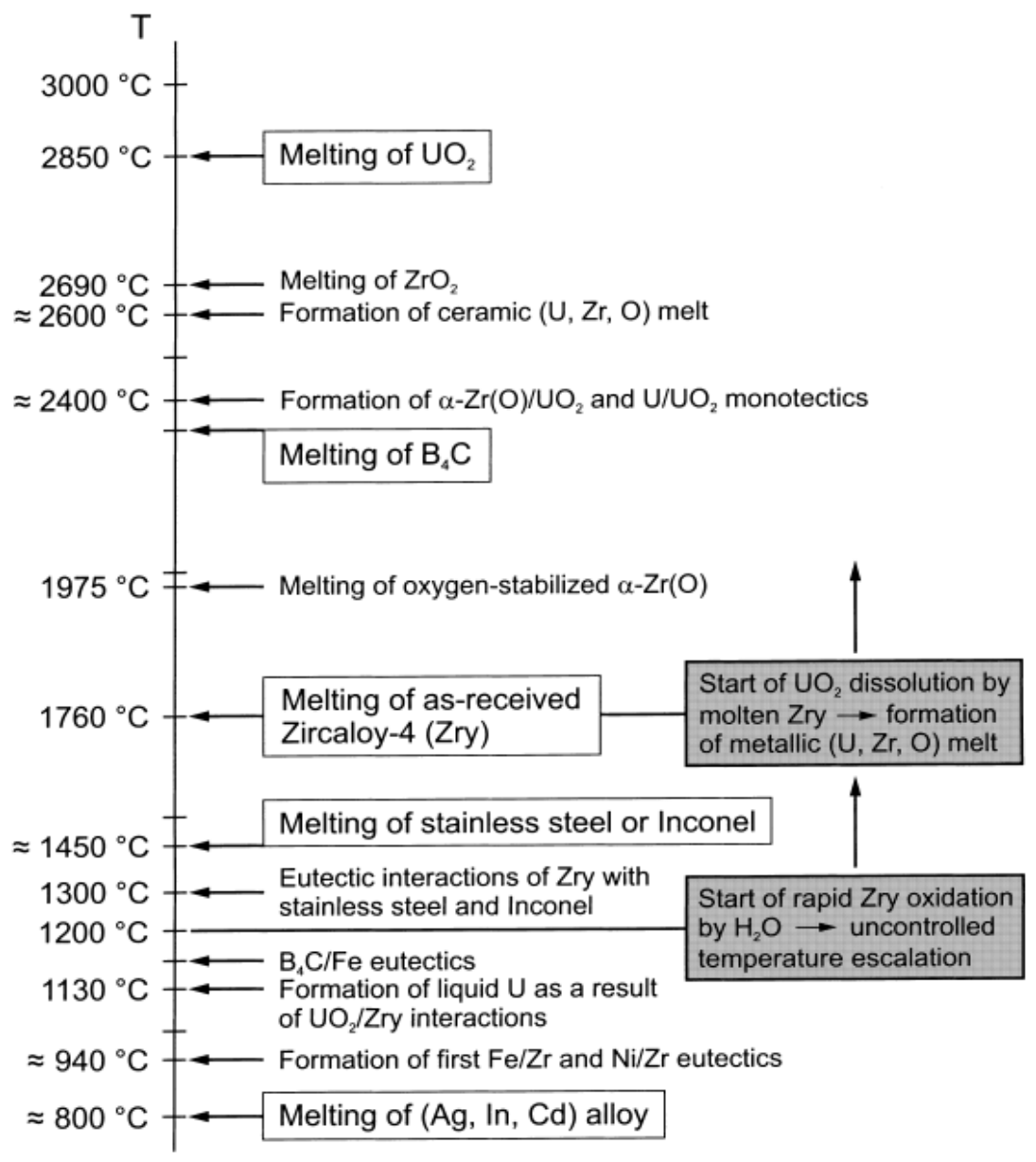

Figure 6. LWR severe accident-relevant melting and chemical interaction temperatures which result in the formation of liquid phases [Reference: P. Hoffman, J. Nuc. Mat. 270 (1999) 194-211].

- Steam oxidation kinetics

- Oxidation rate and associated heat of oxidation (leads to further increased temperature)

- Performance considered for time at elevated temperature and maximum temperature

- Breakaway oxidation may occur if material is held at elevated temperature too long (e.g. time at $\sim 1000 \mathrm{oC}$ before breakaway oxidation occurs should be defined); this phenomenon leads to high hydrogen pickup and cladding embrittlement

- Free hydrogen production and release (combustible $\mathrm{H}_{2}$ production)

- $\quad<1 \%$ metal conversion (based on explosion limits), i.e. $<300 \mathrm{~kg}$ combustible hydrogen

- Maintain ductility following DBA

- Most important accident performance criterion under current licensing standards

- Regulation specifies retention of at least $1 \%$ ductility post-quench

- High temperature mechanical properties 
- Currently not defined in the licensing criteria

- Balloon and burst are not currently defined as a fuel failure

- Burst may occur at different temperatures depending on burnup

- While only a fraction of rods burst, those that do typically burst at $\sim 800{ }^{\circ} \mathrm{C}$; burst may occur at lower temperature with higher burnup due to higher internal pressure

- Burst is a ductile failure

- Size of ballooning and burst opening can be important to the results of the failure

- Desire "graceful" failure

- Severing and/or shattering the clad with subsequent fuel release are considered failure per U.S. requirements

- Creep performance must be considered

- Flow blockage under accident scenarios

- Required calculation for licensing

- Related to maintaining coolable geometry

- Flow blockage may result from swelling / ballooning of clad

- Thermal shock resistance

- Current cladding alloys do not shatter until they have reached high oxidation levels ( $>17 \%$ of the cladding wall thickness consumed by oxidation)

- Standard test applied to determine thermal shock performance

\subsection{Attributes for Advanced Cladding Options}

As an initiator to the cladding discussion, several attributes for accident tolerant cladding were suggested by programmatic leadership. Suggested attributes include improved reaction kinetics with steam, slower hydrogen generation rate, and improved cladding properties overall. The cladding breakout discussion group suggests that these attributes be refined to recognize the direct relation between reaction kinetics and hydrogen generation rate, to better reflect the specific function of nuclear fuel cladding, and to reflect the practical aspects of implementing alternate cladding materials. Hence, the discussion group suggests the following performance bins for assessment of accident tolerant cladding options:

(1) Acceptable performance under normal operating conditions

(2) Ability to maintain coolable geometry under specified accident scenarios

a. DB LOCA, long term operation at or below $1204^{\circ} \mathrm{C}$

b. BDB LOCA, long term operation at $>1204^{\circ} \mathrm{C}$

(3) Improved reaction kinetics as it relates to:

a. Reduced hydrogen generation / generation rate 
b. Behavior under oxygen / steam attack (oxidation rate, heat of oxidation, reaction products)

(4) Economics and fabricability

Several desirable attributes for advanced accident tolerant cladding were defined via application of these performance bins, as summarized below. It was noted that the cladding performance / property envelopes should be defined for each key parameter to allow sensitivity analyses to be conducted for proposed cladding options. These analyses can be used to better define the desired range of characteristics in order to better determine specific materials that may be able to meet the requirements versus first identifying specific materials, then conducting detailed analyses to determine the expected performance of that specific material.

Additional constraints applied to an alternate fuel / cladding system were also identified. Most significantly, the current study applies only to fuel / cladding that can be adopted in existing commercial LWRs; hence, the bundle geometry cannot be affected by the alternate cladding option such that fuel handling equipment, grid plates, and coolant flow will not be impacted. This constraint opens a variety of questions, such as fuel enrichment. Although the enrichment falls more directly into the fuel breakout group, some potentially desirable cladding options would require fuel enrichment above the current standard of less than $5.0 \mathrm{wt} \%$ limit (4.95\% typical) to maintain criticality over the desired fuel pin operating lifetime. In the near term, it is expected that an alternate cladding / fuel system cannot have a significant neutronic impact due to associated changes that would be required for licensing of both the fuel fabrication plant and the nuclear power plant, fabrication handling equipment, fuel transport, and plant operations. Additionally, it was noted that the impact of advanced fuel and cladding materials would be limited if the analyses is not extended beyond the cladding to also consider core materials. Analyses should be broadened to consider clad / grid interactions, possible replacement of control blades, grid structure, etc.

Desirable Accident Tolerant Fuel Attributes

In identifying acceptable cladding properties and analyzing options, one must consider the integral fuel and reactor system. Some properties may have a large margin in the current system, such that they could potentially be impacted (reducing margin) to allow significant improvement in other performance areas.

\section{- Acceptable cladding properties (vs. improved)}

- Should maintain favorable neutronics

- Should not balloon / burst in accident scenarios, with the primary goal being to contain fission products

- Demonstrate thermal shock resistance

- Resistant to irradiation assisted stress corrosion cracking (IASCC)

- General corrosion resistance

- Cannot spall off with coolant flow (erosion resistance)

- Demonstrate minimal release of activated corrosion products into cooling water

\section{- Improved reaction kinetics w/steam}

- Suggested reaction rate reduction of $\sim$ two orders of magnitude based on quick assessment calculations (ORNL, Terrani) 
- Reduced heat of oxidation (secondary to reaction rate reduction)

- Thermodynamic stability with high temperature steam

- Reduced hydrogen generation rate (tied directly to oxidation kinetics)

- Consider effect of other reaction products, i.e. effect on water chemistry, impact of gases produced (hydrogen, carbon monoxide, etc.)

- Fission product retention

- Primary goal: retention of solid material within fuel rod to allow reactor to maintain coolable geometry

- Secondary goal: containment of gaseous fission products

- Parameters must be established at a pre-determined burnup limit

Once the desired attributes are clearly defined and agreed upon, measurement and analysis techniques must be identified, including any applicable measurement or test standards that should be employed. As we approach measurement and testing for candidate materials, the key material properties should be identified with the associated characterization techniques to ensure commonality of measurements across material options, testing envelopes should be defined, and identified measurements and tests should be prioritized. Specific test categories and prioritized screening tests are further described below.

\section{Establishing a Common Accident Definition}

A significant concern was noted with regard to setting common measures and definitions across the various parties involved in accident tolerant fuel development. A variety of DB and BDB accidents could be considered for analysis of fuel system performance; a common metric for accident progression should be established through engagement of accident experts to ensure that all candidate systems are evaluated equally. Accident definition must establish a limiting case; accidents are expected to include specific progressions for standard LOCA events (small break and large break) and station blackout (short term and long term). In selecting transients, consideration should be given to selection based on conservative estimates, best estimates or licensing limits. A separate workshop or focused discussion group may be required to engage the necessary experts in defining baseline accident progressions for use in accident tolerant fuel development, analysis, and testing.

It was noted that work scopes have already been defined for projects awarded to industry and universities under Funding Opportunity Announcements (FOAs) and Integrated Research Projects (IRPs), such that addition of tests based on the accident definition and metrics study may not be possible. However, clear definition of common accident progressions and required measurements may help provide improved focus and definition to test matrices and associated analyses that will guide follow-on work and down selection.

\subsection{Testing Advanced Cladding Materials}

Establishment of a test matrix shall include all licensing criteria and shall identify existing test standards or areas in which test standards must be developed for future qualification. Test categories and expected test details are provided below.

\section{- Steam testing}


- Identify leading candidates via large array of tests of cladding coupons, followed by short tubes, before conducting a reduced test matrix w/full rodlets under accident conditions

- Desire to demonstrate "longer" survival at elevated temperature before loss of strength and ductility relative to the current system

Note: No specific, desired coping time has yet been defined for accident tolerant fuels. However, it is assumed that a minimum increase in the anticipated survival time on the order of hours would be required for the industry to consider pursuing advanced cladding options.

- Test matrix must establish:

- temperature ramp rate

- hold time at $800 \mathrm{C}, 1000 \mathrm{C}, 1204 \mathrm{C}$, + higher temperature testing

- Matrix of environmental conditions:

- $100 \% \mathrm{H}_{2} \mathrm{O}$ steam at atmospheric pressure and at elevated pressure (once-through test)

- Mixed steam / hydrogen environment

- Quench - simulate injection of emergency core cooling system (ECCS)

- Steam shock test - expose heated cladding with dry steam (e.g. cladding at 1400 C shocked with $1000 \mathrm{C}$ steam)

- Quench cladding at lower T (e.g. 800C) to basically freeze the H2 in (H2 precipitates out at higher T); could set a worst case for loss of ductility

- Measure mechanical properties before / after steam exposure

- Tensile test, burst test, ring compression test (post-LOCA screening test for ductility)

- Measurement of onset of oxidation, oxidation rate, and heat of oxidation for specified conditions

- Chemical interactions with other core materials, and expected temperatures at which those interactions might be expected to occur, should also be considered (especially for BDBA conditions)

\section{- Pellet-Clad Chemical Interaction (PCCI)}

- Diffusion couples, set of temperatures in helium environment, at pressure

- Test at nominal conditions - operating temperature with contact between fuel and cladding

- $\quad$ Test under stress at possible accident temperatures - $1130 \mathrm{C}, 1204 \mathrm{C}, \ldots$

- Test temperatures should be established based on knowledge of eutectic formation in the proposed fuel / clad system

\section{- Erosion flow testing - nominal}

- Flow velocity, thermal cycling, water chemistry control ( $\mathrm{pH}$, dissolved $\mathrm{O} 2$, contaminants)

- Assess adhesion of coatings, spalling off of material

- Evaluate effects of friction, wear and fretting 
- Determine effect of cladding selection (surface features) on heat transfer coefficient, departure from nuclear boiling (DNB), etc.

- Stress corrosion cracking of cladding in coolant environment (autoclave test)

- Evaluate cold (pre-irradiation) and neutron irradiated material

- Assess material stability

- Irradiation creep

- Coefficient of thermal expansion (CTE) mismatch (particularly important for hybrid cladding options)

- Test w/external pressure on tube

- Coupon test under neutron irradiation

- Look at test $w / 0.5-1 \%$ creep down

- Drop test (1-ft and 30-ft) - transport, 10 CFR 71

- Conduct normal tensile test first; determine break point for strain

- Fuel and cladding material should not deform at established acceleration limits (shock testing for fresh fuel)

- Standard corrosion testing (nominal conditions)

- Mechanical properties measurement

- Tensile testing (cold, at temperature, after irradiation) - hoop and axial [coupons]

- Burst (pressurize to failure) - at room T and elevated T ( $\sim 350 \mathrm{C})$; higher temperature testing for LOCA analysis

- Fracture toughness (testing of cold, elevated temperature, and irradiated sample coupons; success criteria must be established)

- Fatigue testing - standard test for Zr-based clad (vendors currently conduct these tests) no initiation of fatigue after $\mathrm{X}$ cycles; used to determine safe stress level

- Cyclic loading under basic reactor conditions

- Need to obtain vendor input for further clarification

- Ductile to brittle transition - before and after irradiation

- Irradiation studies - analysis should be conducted to clarify potential value and limits of ion irradiation for initial comparative studies of candidate materials

- Measurement of thermophysical-mechanical properties - unirradiated and irradiated

- Elastic properties

- Density

- Thermal Conductivity

- Heat capacity

- Diffusivity 
- Emissivity

- Microstructure and microstructure evolution

- Processing-induced differences, radiation damage, multi-layer cladding issues

\section{- Tritium permeation}

- Fabrication related issues (e.g., ability to fabricate long tubes)

- Robustness tests (e.g., handling concerns)

- Standards for insertion into grid, hardness, scratching

- Acceptable scratch for current cladding - maximum $9 \%$ of wall thickness

- Microhardness measurement

- Assessment of joining issues (overall hermeticity, weldability, joint mechanical strength, etc.

\section{Prioritized Screening Tests}

Based on the desired attributes and initial assessment of tests required to assess the performance of potential cladding options, a prioritized list of screening tests was developed for each "class" of potential cladding materials. These lists were developed for fully metallic cladding, fully ceramic cladding, and hybrid cladding, which could include coatings or wraps on an inner tubular clad. Prioritization of tests assumes that based on known properties, the candidate material meets basic requirements for use in a fuel rod. As additional data are generated, one must reassess impact of the test and measurement results on the ability to design a function fuel pin. Details for each of the screening tests were provided in the previous section.

\section{Metallic Cladding}

1. Steam oxidation, post-steam ductility / strength tests

2. Environmental testing (corrosion, IASCC, SCC, erosion)

3. Basic chemical compatibility at nominal conditions

4. Irradiation environmental testing (sample coupons; determine effects on mechanical properties)

5. Mechanical testing (assuming baseline unirradiated data already available, additional mechanical tests would not be required until after a materials has passed the other screening tests identified)

\section{Ceramic Cladding}

1. Mechanical integrity tests (includes hermeticity, break)

2. Steam oxidation

3. Basic chemical compatibility at nominal conditions

4. Environmental testing - LWR water exposure, range of chemistry conditions

5. Mechanical testing

6. Irradiation environmental testing (sample coupons)

\section{Coatings on Cladding Tube}

1. Coating adhesion - initial, thermal cycling, with flow (spall), wear (fretting) 
2. Based on substrate and "coating", follow metallic or ceramic cladding priorities

a. Environmental testing w/small exposed region

b. Chemical compatibility to include coating / substrate compatibility (establish temperature limit)

Note for hybrid cladding options: During cladding fabrication, the substrate must retain sufficient corrosion resistance and mechanical properties (e.g. annealing temperatures).

Cladding candidates that pass the initial screening tests should be considered for more detailed testing in the correct geometry and environments (e.g. fueled rodlets). 


\section{Breakout Session Summary: Advanced Nuclear Fuels}

Attribute Set: Improved fuel and cladding thermo-mechanical properties and fission product retention.

Participants:

Chris Stanek, LANL (Session Lead)

Ted Besmann, ORNL

Ken McClellan, LANL

Jon Carmack, INL

Bo Cheng, EPRI

Dick Hobbins, contractor

Robert Montgomery, PNNL

Andrew Nelson, LANL

James Hobbs, NFS

Ron Omberg, PNNL

Rory Kennedy, INL

Jeff Powers, ORNL

Ed Lahoda, Westinghouse

Joy Rempe, INL

Jim Tulenko, University of Florida

Before discussing the results of the "Improved Fuel and Cladding Thermo-Mechanical Properties-Fission Product Retention" breakout session, it is worth summarizing how the breakout session group interpreted the guidance from the meeting organizers. First, we noted that the motivation for this workshop was due to language present in the Consolidated Appropriations Act, 2012, Conference Report 112-75, the Department of Energy, Office of Nuclear Energy was: Directed "to give priority to developing enhanced fuels and cladding for light water reactors to improve safety in the event of accidents in the reactor or spent fuel pools," and further urged " that special technical emphasis and funding priority be given to activities aimed at the development and near-term qualification of meltdown-resistant, accident-tolerant nuclear fuels that would enhance the safety of present and future generations of Light Water Reactors," and requested "to report to the Committee, within 90 days of enactment of this act, on its plan for development of meltdown resistant fuels leading to reactor testing and utilization by 2020." Second, we noted that the working definition for Fuels with Enhanced Accident Tolerance are those that, in comparison with the standard $\mathrm{UO}_{2}$-Zircaloy system, can tolerate loss of active cooling in the core for a considerably longer time period (depending on the LWR system and accident scenario) while maintaining or improving the fuel performance during normal operations. This information served as important context for our discussions related to enhanced accident tolerant fuel designs.

Regarding specific goals of the workshop, among those at a high level included: define "Enhanced Accident Tolerance," identify the tests needed to qualify something as being more accident tolerant, prioritize the most important attributes to test, and develop metrics to be used for evaluation of attribute compliance. Furthermore, we were instructed to consider all accidents (e.g. RIA, LOCA, station blackout, ATWS, etc.) as well as current DBAs. However, we interpreted the primary goal of the breakout sessions to be associated with defining requirements for down-selection among options during the feasibility assessment. The proposed components of this goal include:

1. Identification of important attributes (properties, performance characteristics) for ATF

2. Map the merit of the attributes against potential operational or safety envelope benefits

3. If possible, quantify the target value for the attribute/property

4. Define required analyses (accident scenarios) to quantify the target value

In attempt to directly respond to this guidance, the "Improved Fuel and Cladding Thermo-Mechanical Properties-Fission Product Retention" breakout session struggled with how to disentangle the complex and interrelated properties that govern nuclear fuel performance. However, the interrelationship of materials properties that govern fuel performance dictated that we were only able to directly address several of the requests mentioned above. For the specific goals where we were unable to provide a direct 
response, we rather provided a description for a systematic approach to assess the enhanced safety characteristics of a particular fuel design, which will still provide a capability to perform a down selection of advanced fuel designs. Nevertheless, in the following section, the results of each of the four goals described above are described.

\subsection{Approach and Results}

The initial effort by the group was to develop a list of material and behavior properties (or characteristics) for the fuel pellet and clad system that influence the thermal, mechanical, and chemical performance of the fuel and that furthermore impact the desired attributes of the fuel. These attributes include maintaining component chemical and dimensional stability, retaining fission products, and not impacting reactivity control systems during normal operation and accident conditions. Once these properties were identified, we discussed and identified the role of each property/characteristic relative to a set of operating conditions that spanned normal operation to severe accidents. A description of the seven different operating and accident scenarios/conditions is contained in Appendix A.

The fuel properties and corresponding attributes for different operating conditions are provided in the tables at the end of this report (i.e. Goal 1 above). It is worth noting that these properties were categorized according to Thermal, Mechanical, Chemical, Neutronics and Other, which will become important when we describe conversion of these properties into enhanced accident tolerance metrics. By describing the implication of each materials property to an operating condition, we have attempted to "map the merit of the attributes against potential operational or safety envelope benefits (i.e. Goal 2 from above).

Regarding Goals 3 and 4 from above (i.e. quantify the target value for the attribute/property and define required analyses (accident scenarios) to quantify the target value), due to the interrelationship between the materials properties listed in the tables at the end of this report, it is not possible to provide target values for any one specific property. Rather, it is important to consider the integrated effects of the combination of materials properties of any particular advanced fuel design. Therefore, we have developed a systematic analysis approach to assess enhanced accident tolerant fuel concepts. It is expected that this type of approach would be used in the down selection of candidate fuel designs. A diagram of this approach is provided in Figure 7. It is worth noting that in developing this approach, we attempted to not necessarily bias the approach to $\mathrm{Zr}-\mathrm{UO}_{2}$ designs, as will become apparent during the description of the approach. We start description of this diagram from the bottom. The maroon box on the bottom of the diagram corresponds to all of the materials properties and characteristics necessary to do a fuel performance calculation. For the most part, these properties are described in the tables at the end of this report. The next step moving up the diagram is a green box, which consists of the necessary behavioral models required to perform a fuel performance simulation. Of course, these models will consist of the materials models previously described, which will come from validated models, experimental data or assumptions. At this point, and as is evident in the diagram, an assessment of the behavioral models that exist for the advanced fuel design being proposed must be assessed. It is our opinion that the onus is on the group proposing any particular design to provide a collection of behavioral models with a full description of the source of the data and/or assumption relied upon to generate the models. Another way to view this assessment is as a first step in an advanced fuel down selection process. That is, if the behavioral models are deemed adequate to perform a fuel performance calculation, then the evaluation should proceed. However, if the models or the data used to generate them are deemed to be inadequate, then effort should be redirected on generating the necessary data to develop adequate 
models, rather than continue an attempt to assess the enhanced safety aspects of a design that fails this assessment.

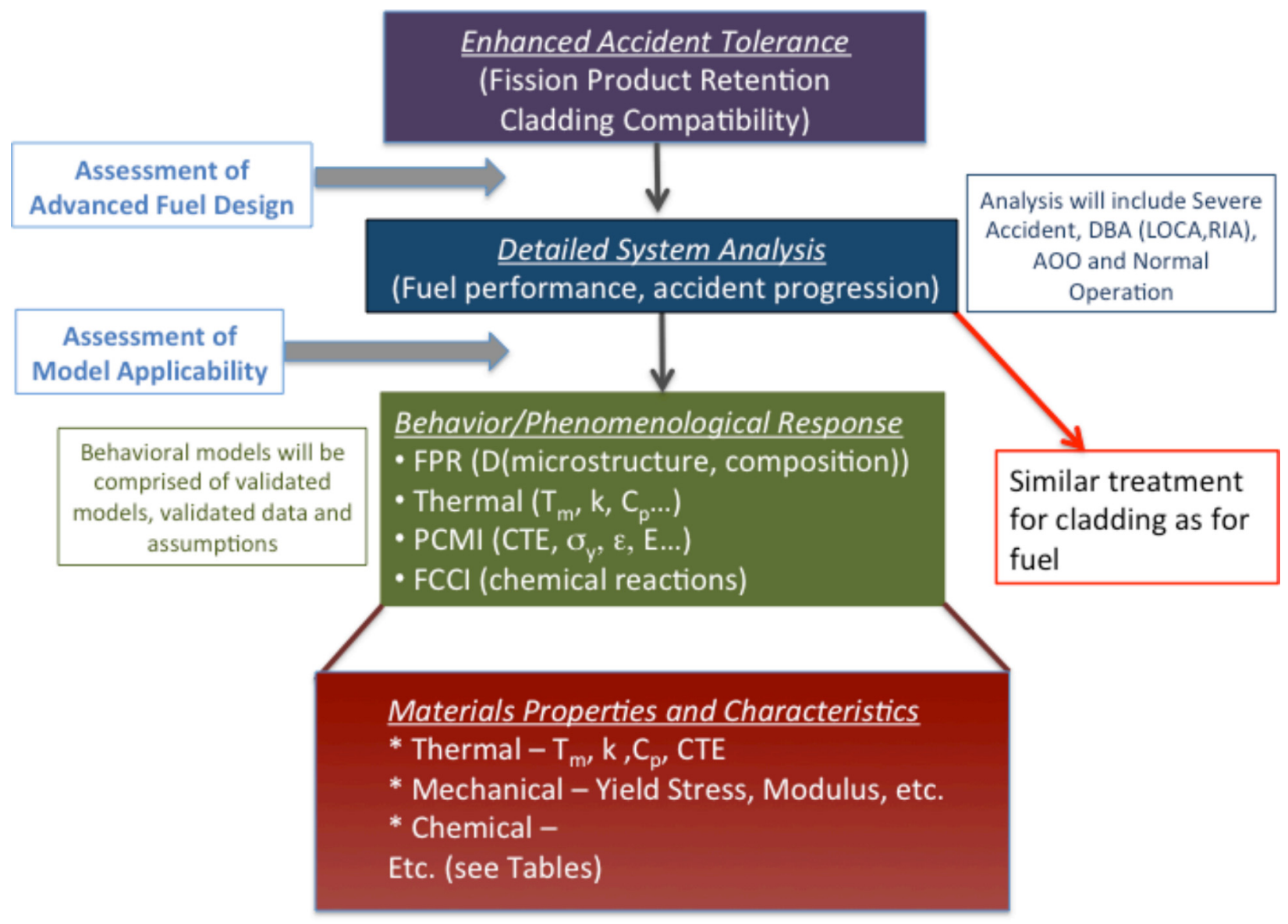

Figure 7. A diagram that describes an approach to assessing the enhanced accident attributes of a proposed fuel design.

At this point (i.e. a particular fuel design and associated behavioral models have passed an initial analysis), a detailed analysis of fuel performance and accident progression can be performed with the computational tools currently available (blue box in Figure 7). For an integrated analysis, such codes are as follows: severe accident behavior (e.g. MELCOR, MAAP), design basis accidents (e.g.

RELAP/RETRAN), core depletion (e.g. CASMO/SIMULATE). For single effects analysis, such codes are: for fuel performance analysis (e.g. FRAPCON/FRAPTRAN, FALCON) and focused codes on specialized/unique properties (e.g. Olander approach). After such an analysis has been performed, sufficient information to perform an assessment of a particular design's enhanced accident attributes (as denoted on Figure 7). In performing this assessment, it is important to identify the objectives, e.g. as good or better as $\mathrm{UO}_{2}-\mathrm{Zr}$ in safety and performance, and identify requirements to meet performance/safety objectives, e.g. fission product retention, cladding stress, fuel-cladding reaction layer, fraction of melt, etc. That is, calculations are performed using applicable codes/tools with representative models/data to compare baseline $\left(\mathrm{UO}_{2}-\mathrm{Zr}\right)$ and new designs under different accident scenarios. In order to compare an advanced design to the $\mathrm{UO}_{2}-\mathrm{Zr}$ baseline, it is necessary to establish weighting/importance factors for the various scenarios and requirements. A notional example of this type of multicomponent assessment is provided in Table 1, where for a certain operating scenario (e.g. severe accident) and range 
of representative phenomena are tabulated for several different fuel designs. Then, based upon the weighting factors described, it is possible to rank advanced fuel designs. This illustrates that numerous phenomena must be simultaneously considered.

Table 1. Example of multicomponent assessment of enhanced ATF designs

\begin{tabular}{|c|c|c|c|c|}
\hline & $v \mathrm{O}_{2} \mathrm{zr}$ & Design 1 & Design 2 & Design 3 \\
\hline $\begin{array}{l}\text { Fission Product } \\
\text { Release }\end{array}$ & 1.0 & 1.5 & 0.5 & 3.0 \\
\hline $\begin{array}{l}\text { Cladding } \\
\text { Stress }\end{array}$ & & & & \\
\hline $\begin{array}{l}\mathrm{P}=\mathrm{C} \text { reaction } \\
\text { layer }\end{array}$ & & & & \\
\hline
\end{tabular}

Table 2 provides a tabulation of the importance and applicability of material properties to operational regimes. The relative importance of the material property during the regime is summarized. For example, the fuel melt temperature is an important fuel attribute during all operational conditions as explained in the table. 


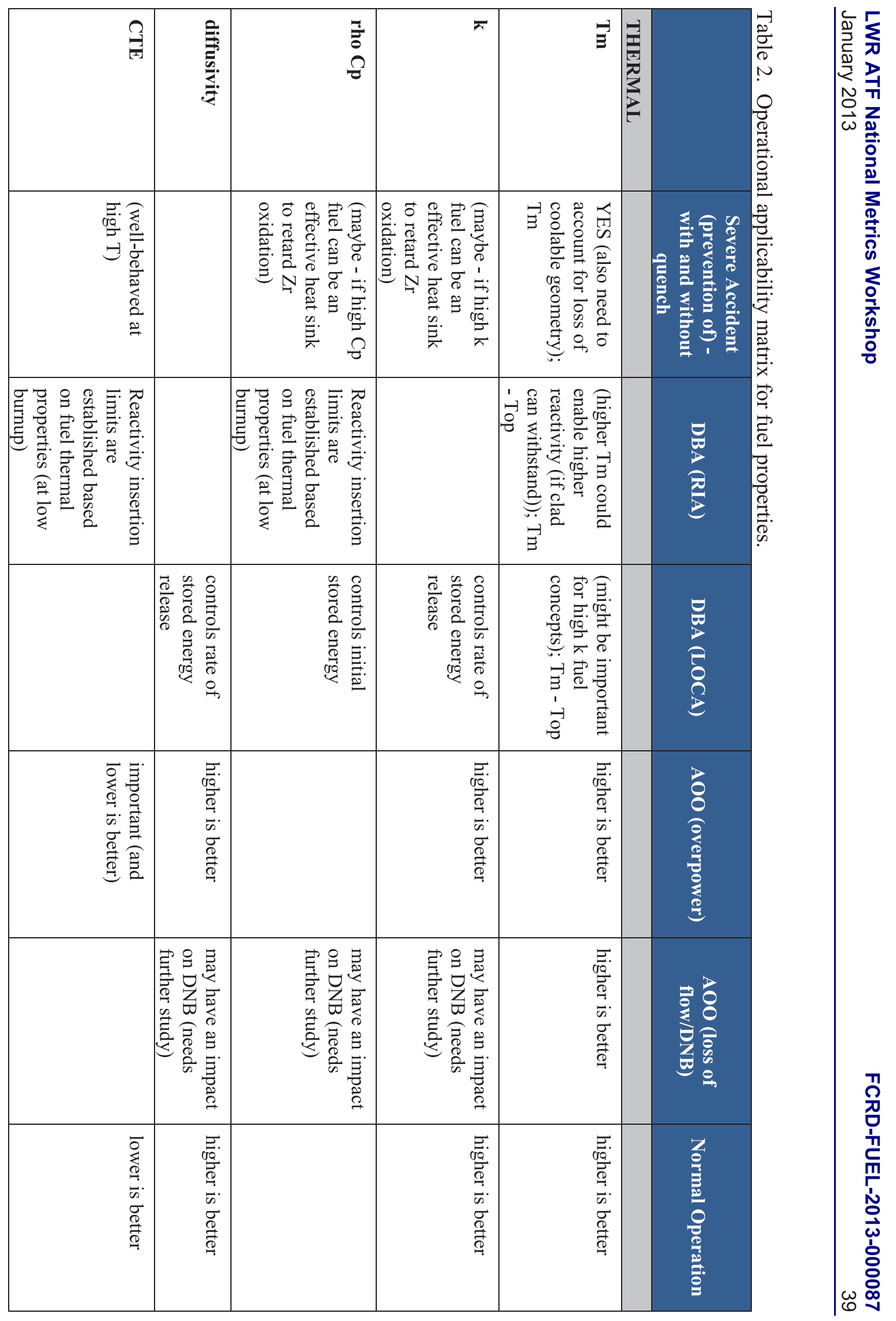




\begin{tabular}{|c|c|c|c|c|c|c|c|c|c|}
\hline 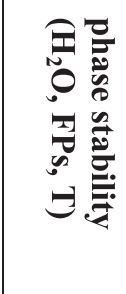 & 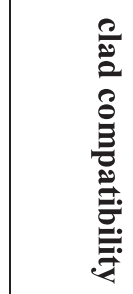 & 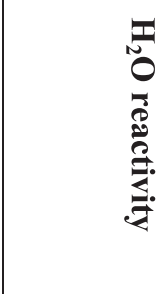 & 翻 & 总 & $\begin{array}{l}\frac{2}{0} \\
\frac{8}{8} \\
\frac{2}{0} \\
0\end{array}$ & 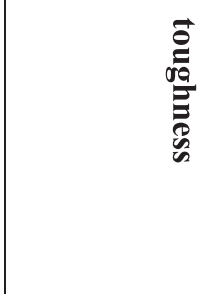 & 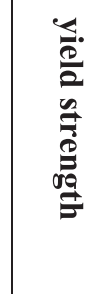 & 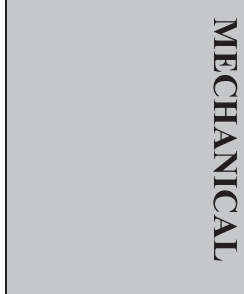 & \\
\hline 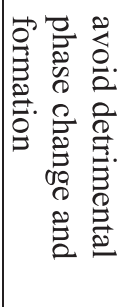 & 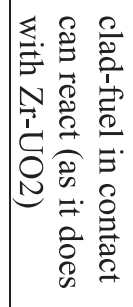 & 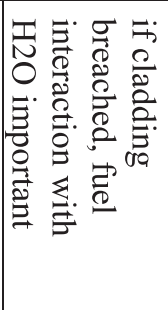 & & & 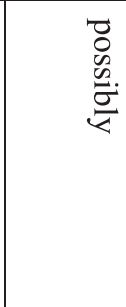 & 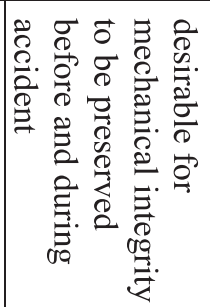 & 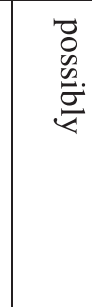 & & 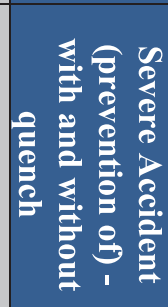 \\
\hline \multirow[t]{2}{*}{ 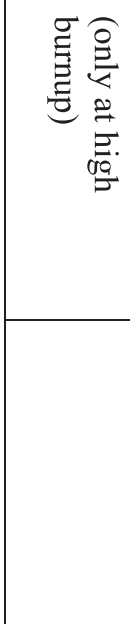 } & & & & & 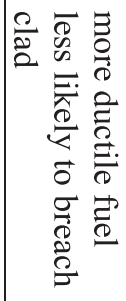 & & & & 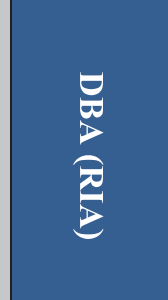 \\
\hline & 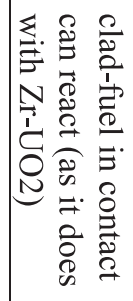 & 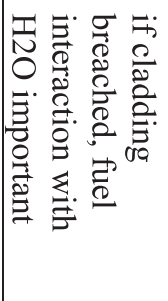 & & & & 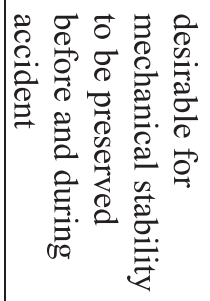 & & & 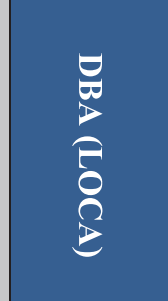 \\
\hline 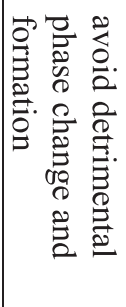 & 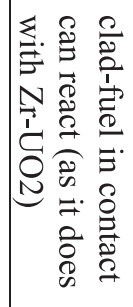 & & & 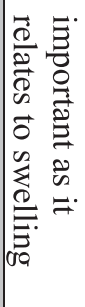 & 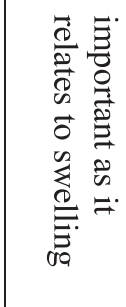 & 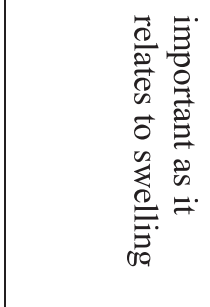 & 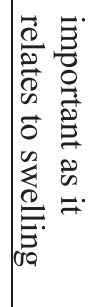 & & $\begin{array}{l}8 \\
8 \\
0 \\
0 \\
0 \\
\frac{8}{0} \\
0 \\
\frac{8}{3}\end{array}$ \\
\hline 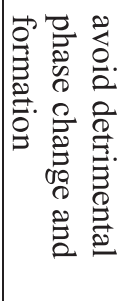 & 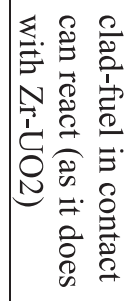 & & & 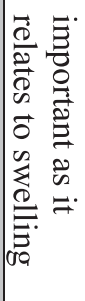 & 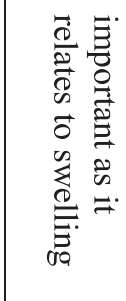 & 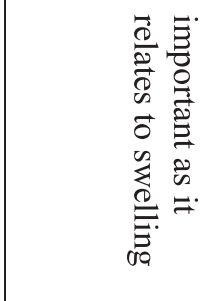 & 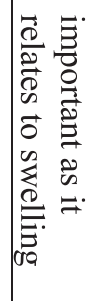 & & 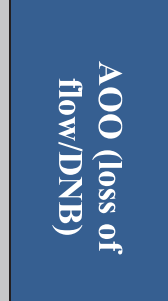 \\
\hline 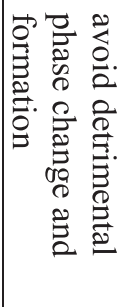 & 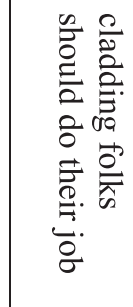 & 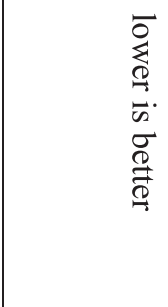 & & 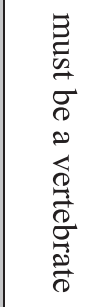 & 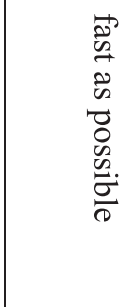 & 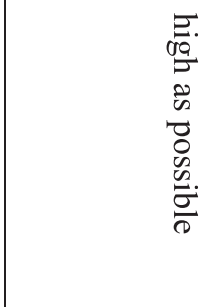 & 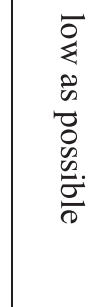 & 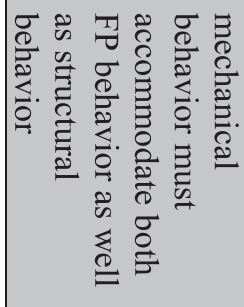 & 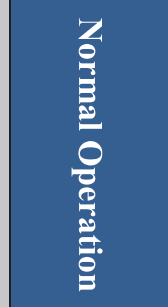 \\
\hline
\end{tabular}




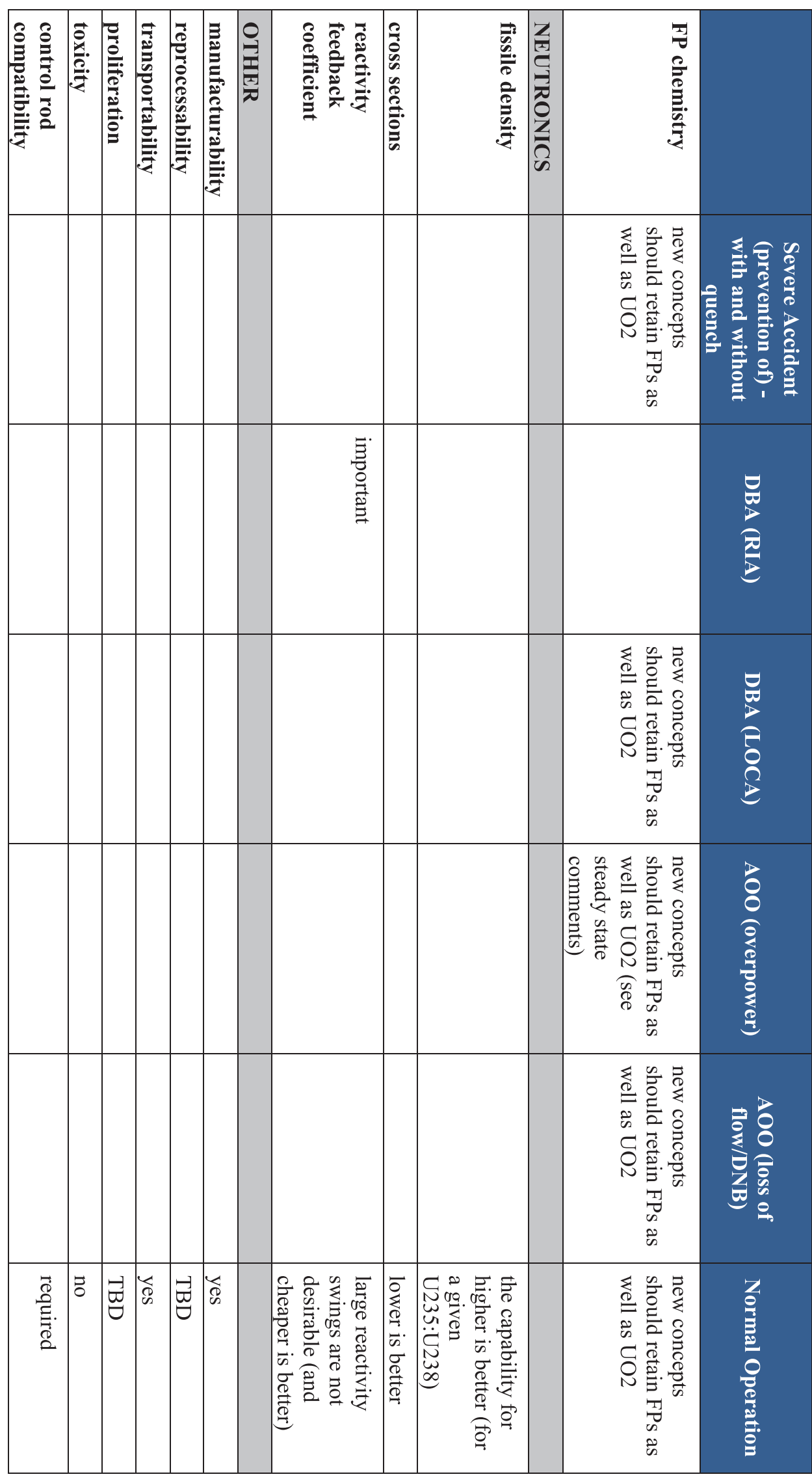




\title{
5. Breakout Session Summary: Operations/Safety Constraints
}

\author{
Constraints: Current LWR designs, operational and safety envelope, economic impacts, definition of \\ representative accident scenario, etc.
}

As a part of the 2-day Enhanced Accident Tolerant LWR Fuels (ATF) National Metrics Workshop, the Session 3 team worked to address the constraints and considerations related to the deployment of ATF in existing commercial power reactors within the desired time frames. The ATF objectives include a near term (10 year time frame) demonstration in a commercial LWR, with the long term objective of implementing the ATF as a primary fuel for commercial LWRs.

Session 3 team members included:

Andrew Solder (EPRI)
Buzz Savage (DOE)
Cetin Unal (LANL)
Don Williams (ORNL)
John Voglewede (NRC)
Kathy McCarthy (INL)

Andrew Solder (EPRI)

\author{
Larry Ott (ORNL) \\ Mike Todosow (BNL) \\ Paul Murray (AREVA) \\ Rich Kochendarfer (AREVA) \\ Rose Montgomery (TVA, Session Chair) \\ Temi Taiwo (ANL)
}

The team began the process with a broad discussion of the Session 3 assignment. The team reviewed the suggested parameters presented in the workshop's general session, discussed the recommendations made at previous FCRD meetings by the INL Industry Advisory Committee, and considered the parameters proposed within the workshop reference document "Nuclear Fuel Safety Criteria Technical Review, Second Edition" (NEA No. 7072, OECD 2012 ).

Given the program objectives of an LTA demonstration in a commercial LWR within 10 years and following ATF implementation, the team elected to split the guidance between LTAs and reload fuel, as the requirements for a limited demonstration may be less rigorous than those for routine reload (full core) use. Thus, the team consolidated the suggested parameters to a single list and, where deemed appropriate, offered suggested performance metrics, as provided in Table 3. If the metric was to be addressed by other Sessions, or if the team agreed it was unnecessary to the ATF work, no guidance was provided and the parameter was either removed from the listing or a note to this effect was provided within the table. In some cases, the team did not come to a consensus on guidance for the parameter, and in these categories the main discussion points and remaining questions were recorded. In other areas the team noted some improvements that could be incorporated to the metric with additional, easily obtained information that was not accessible during the Workshop.

The team invested a significant amount of discussion on a few key topics, including:

- Considerations for potential ATF geometry deviations from traditional fuel geometries operated in existing LWRs and compatibility with co-resident fuel. These are captured within the parameter metrics provided in Table 3.

- Recommendations, as listed in Table 3, to ensure that ATF concepts are rigorously evaluated for parameters other than accident condition oxidation kinetics and fuel temperature effects prior to LTA operation, including: 
- A Failure Modes and Effects Analysis (FMEA) to be completed prior to ATF insertion to ensure that any potential ATF operating vulnerabilities are recognized and mitigated as possible;

- Completion of a 50.59-like process to illuminate any necessary licensing or logistical preparations for operation of the ATF in a commercial LWR.

- Quantifying the recommended minimum additional coping time to be provided by the ATF; the team concluded that this should be studied in much more detail and would take more time than was available to the workshop. Thus, the team did not recommend a metric. Table 3 does include some notes from the teams' discussion.

- The need to include a metric to address those concepts that require enrichments greater than 5 $w t \%$. After long discussion, the recommendation was to acknowledge that there is an inherent limitation in the existing commercial industry infrastructure, and therefore concepts that do not rely on higher enrichment are preferred. However, the recommended metric does not exclude concepts requiring higher enrichment. If the industry restrictions on higher enrichments are eliminated, this metric should be revisited.

- The varying, but equally relevant, levels of operational requirements, including industry preferences, licensing requirements, and proof of concept considerations.

- It is important to recognize that the utility's requirements for reactor operation do not end with the licensing regulations, they begin there. Also, the mission of the commercial power utility is to make electricity, not to test new fuels. Thus, there is an inherent reluctance to introduce demonstration programs that bring risk to power production activities, require additional licensing activities, or impact refueling outage activities. Any AFT operation must necessarily address and minimize these impacts on the utility by ensuring (as possible) full compatibility with co-resident fuel and reactor components, and by limiting perturbations of the normal operation of the plant.

- Industry procedures and precedents require the supporting evidence for prototype operation to be scaled to the relative change from existing fuel, as illustrated by the 50.59 process and the commercial grade dedication process. Large changes typically require extensive supporting evidence and evaluations prior to operation, while very small modifications to an existing design might be implemented with minimal effort. Thus, industry representatives attending FCRD and ATF meetings have repeatedly suggested that there is a preference for implementing design changes in an evolutionary manner and a phased approach towards an ATF demonstration is preferred. For example some ATF concepts proposed for final use at $20 \mathrm{wt} \%$ enrichment may be more easily included if a lower enrichment is used for the demonstration. Or, as another example, a new fuel material proposed with a new clad material may need to be demonstrated individually to begin, with the pellets encased in zirconium-based alloy clad and the clad introduced as a hollow tube or coupon. Also, operation of the concept in rod form is strongly recommended as a precursor to assembly insertion.

- Some metrics to address these considerations are provided in Table 3.

- Discussions on the necessity to minimize the cost for ATF. It is well known that the commercial nuclear industry has optimized the current zirc-clad $\mathrm{UO}_{2}$ fuel over several decades, that the current fuel design represents a large financial investment by fuel vendors and utilities, and that the current designs are considered very reliable and safe. Thus, it is postulated that the additional 
cost of ATF must be relatively low. However, the team could not produce quantitative results within the time allotted.

\subsection{Fuel Fabrication/Reactor Operation Metrics}

It should be noted that, after clarification by the workshop organizers, the only areas of the fuel cycle that were addressed were fuel fabrication and reactor operation. Other areas were neglected in the interest of time. Items noted for improvements to Table 3 during the closing general session included providing a prioritization for the listing and adding values for current fuel as appropriate. It should be further noted that the team does not consider this listing to be comprehensive; however, it does address the majority of the important considerations for commercial reactor operation.

\section{Table 3. Session 3 Metrics Listing}

Note: Comparisons against current or co-resident fuel are synonymous with zirconium-based alloy clad $\mathrm{UO}_{2}$ and current reactor implies existing commercial power reactors.

\begin{tabular}{|c|c|c|}
\hline Subcategory & LTA/LTR (10 year objective) & Reload/Full Core \\
\hline $\begin{array}{l}\text { External Assembly envelope } \\
\text { (assembly-assembly pitch) }\end{array}$ & $\begin{array}{l}\text { Must fit within current reactor } \\
\text { envelope with minimal changes. } \\
\text { Must be compatible with fuel } \\
\text { handling equipment. Some non- } \\
\text { fuel components may be modified. }\end{array}$ & $\begin{array}{l}\text { Modifications may be specified for } \\
\text { mechanical support features or } \\
\text { geometric shapes (reactor internals or } \\
\text { fuel) - this should be noted within the } \\
\text { design. }\end{array}$ \\
\hline Array & $\begin{array}{l}\text { Location of the instrumentation } \\
\text { tube in PWR (instrumented } \\
\text { location preferred) needs to be } \\
\text { considered, GT locations should be } \\
\text { same if operated in rodded location } \\
\text { (including clearances). [note BWR } \\
\text { will not require these constraints.] }\end{array}$ & $\begin{array}{l}\text { Modifications can be made - this } \\
\text { should be noted within the design. }\end{array}$ \\
\hline Assembly structure & $\begin{array}{l}\text { Prefer structure \& materials similar } \\
\text { to co-resident fuel }\end{array}$ & $\begin{array}{l}\text { Modifications can be made - this } \\
\text { should be noted within the design. }\end{array}$ \\
\hline Rod OD & $\begin{array}{l}\text { Co-resident rod OD preferred. } \\
\text { Note that there may be } \\
\text { manufacturing obstacles if the rod } \\
\text { OD differs. }\end{array}$ & $\begin{array}{l}\text { Modifications can be made - this } \\
\text { should be noted within the design. }\end{array}$ \\
\hline Pellet configuration & $\begin{array}{l}\text { Should not negatively impact fuel } \\
\text { performance. }\end{array}$ & $\begin{array}{l}\text { Modifications can be made - this } \\
\text { should be noted within the design. }\end{array}$ \\
\hline Thermal Hydraulics & $\begin{array}{l}\text { Allow operation (e.g., pressure } \\
\text { drops, fuel liftoff, and cross flow) } \\
\text { in mixed core with current fuel } \\
\text { designs. }\end{array}$ & Same or better performance \\
\hline Neutronics & $\begin{array}{l}\text { Should not adversely impact core } \\
\text { performance or limits. }\end{array}$ & $\begin{array}{l}\text { Should not negatively impact power } \\
\text { production. Compliance with current } \\
\text { operational limits is preferred. }\end{array}$ \\
\hline \multicolumn{3}{|c|}{ esign Characteristics (geometry considerations) } \\
\hline Subcategory & LTA/LTR (10 year objective) & Reload/Full Core \\
\hline Material strength & $\begin{array}{l}\text { Risk of failure should be } \\
\text { reasonably low during shipping / }\end{array}$ & $\begin{array}{l}\text { Material strength must be sufficient to } \\
\text { allow typical shipping\& handling }\end{array}$ \\
\hline
\end{tabular}




\begin{tabular}{|c|c|c|}
\hline & $\begin{array}{l}\text { handling and all conditions of } \\
\text { operation. }\end{array}$ & $\begin{array}{l}\text { loads, normal operating loads, AOOs } \\
\text { and transient / accident conditions } \\
\text { considering temperature and } \\
\text { irradiation. }\end{array}$ \\
\hline Control component interface & $\begin{array}{l}\text { Must interface with control } \\
\text { component or consider operating in } \\
\text { non-rodded location }\end{array}$ & $\begin{array}{l}\text { Modifications can be made - this } \\
\text { should be noted within the design. }\end{array}$ \\
\hline Chemistry & $\begin{array}{l}\text { Avoid galvanic corrosion issues } \\
\text { when operated with co-resident } \\
\text { fuel. Must be compatible with } \\
\text { plant coolant chemistry. }\end{array}$ & $\begin{array}{l}\text { Compatible with plant chemistry } \\
\text { program and other reactor } \\
\text { components, including control } \\
\text { components, flow channels, personnel } \\
\text { doses, etc. }\end{array}$ \\
\hline Assembly mass/volume & $\begin{array}{l}\text { Should be similar to co-resident } \\
\text { fuel. Must be compatible with } \\
\text { plant handling equipment. }\end{array}$ & $\begin{array}{l}\text { Modifications can be made - this } \\
\text { should be noted within the design. }\end{array}$ \\
\hline $\begin{array}{l}\text { Dimensional stability (rod } \\
\text { growth/assembly } \\
\text { growth/distortion) }\end{array}$ & $\begin{array}{l}\text { Must be accommodated by existing } \\
\text { plant hardware. }\end{array}$ & $\begin{array}{l}\text { Must be accommodated by existing } \\
\text { plant hardware. }\end{array}$ \\
\hline Debris generation & $\begin{array}{l}\text { Risk of unintended debris } \\
\text { generation (e.g., delamination/ } \\
\text { spalling) should be reasonably low } \\
\text { during all conditions of operation. }\end{array}$ & $\begin{array}{l}\text { Risk of unintended debris generation } \\
\text { (e.g., delamination/ spalling) should } \\
\text { be reasonably low during all } \\
\text { conditions of operation. }\end{array}$ \\
\hline \multicolumn{3}{|l|}{ Normal Operations \& AOO } \\
\hline Subcategory & LTA/LTR (10 year objective) & Reload/Full Core \\
\hline Power capacity & $\begin{array}{l}\text { may run at lower or higher power, } \\
\text { not limiting rod for the core }\end{array}$ & no de-rates \\
\hline Burnup & $\begin{array}{l}\text { Sufficient BU to demonstrate } \\
\text { capability }\end{array}$ & Same or better performance \\
\hline \multicolumn{3}{|l|}{ Normal Operations \& AOO } \\
\hline Subcategory & LTA/LTR (10 year objective) & Reload/Full Core \\
\hline Cycle Length & same as resident assemblies & $\begin{array}{l}\text { Same or longer; Should check on } \\
\text { what the maximum/ optimum could } \\
\text { be for maintenance on other systems }\end{array}$ \\
\hline maneuvering & Should not be limiting. & Same or better performance \\
\hline ramp rates & Should not be limiting. & Same or better performance \\
\hline $\mathrm{AOO}$ & Should not be limiting. & Same or better performance \\
\hline Critical heat flux & $\begin{array}{l}\text { Should not adversely impact core } \\
\text { performance or limits }\end{array}$ & Same or better performance \\
\hline Reactivity coefficients & $\begin{array}{l}\text { Should not adversely impact core } \\
\text { performance or limits }\end{array}$ & Same or better performance \\
\hline Criticality and shutdown margins & $\begin{array}{l}\text { Should not adversely impact core } \\
\text { performance or limits }\end{array}$ & Same or better performance \\
\hline CRUD Deposition & No CRUD magnets. & No CRUD magnets. \\
\hline Oxidation/hydriding & Not addressed in this session. & \\
\hline $\begin{array}{l}\text { Thermo-mechanical loads } \\
\text { (stress/strain//thermal expansion) }\end{array}$ & $\begin{array}{l}\text { Should not adversely impact core } \\
\text { performance or limits }\end{array}$ & Same or better performance \\
\hline Rod gas pressure & Not addressed in this session. & Not addressed in this session. \\
\hline FCI & Not addressed in this session. & Not addressed in this session. \\
\hline
\end{tabular}




\begin{tabular}{|c|c|c|}
\hline centerline fuel temp & Not addressed in this session. & Not addressed in this session. \\
\hline Assembly holddown force & Addressed in other categories. & Addressed in other categories. \\
\hline Fretting wear & Addressed in other categories. & Addressed in other categories. \\
\hline LHGR Limits & $\begin{array}{l}\text { Should not adversely impact core } \\
\text { performance or limits. }\end{array}$ & Same or better performance \\
\hline Peaking factors & $\begin{array}{l}\text { Should not adversely impact core } \\
\text { performance or limits. }\end{array}$ & Same or better performance \\
\hline $\begin{array}{l}\text { Coolant activity } \\
\text { Fuel gap activity } \\
\text { Source term }\end{array}$ & $\begin{array}{l}\text { Should not adversely impact core } \\
\text { performance or limits. [note: } \\
\text { debris \& chemistry categories } \\
\text { include additional information.] }\end{array}$ & Same or better performance \\
\hline \multicolumn{3}{|l|}{ Transients \& Accidents } \\
\hline Subcategory & LTA/LTR (10 year objective) & Reload/Full Core \\
\hline Operations envelope & safety margins same or better & $\begin{array}{l}\text { Chapter } 15 \text {, safety margins same or } \\
\text { better. } \\
\text { Consider defining concept-specific } \\
\text { scenarios, as needed. }\end{array}$ \\
\hline Reflood & $\begin{array}{l}\text { Capable of surviving thermal } \\
\text { shock. Reflood characteristics } \\
\text { should not be adversely impacted } \\
\text { considering expected residence } \\
\text { time in core. }\end{array}$ & Capable of surviving thermal shock. \\
\hline Thermal Hydraulics & $\begin{array}{l}\text { DNB \& rewetting layer are surface } \\
\text { condition and pitch-to-diameter } \\
\text { ratio dependent and should not be } \\
\text { degraded. }\end{array}$ & $\begin{array}{l}\text { DNB \& rewetting layer are surface } \\
\text { condition and pitch-to-diameter ratio } \\
\text { dependent and should not be } \\
\text { degraded. }\end{array}$ \\
\hline Oxidation & $\begin{array}{l}\text { Hydrogen generation should be } \\
\text { significantly reduced. }\end{array}$ & $\begin{array}{l}\text { Hydrogen generation should be } \\
\text { significantly reduced. }\end{array}$ \\
\hline $\begin{array}{l}\text { Initial conditions (accident } \\
\text { scenario specific) }\end{array}$ & $\begin{array}{l}\text { Same or less restrictive are } \\
\text { desirable; however, these should be } \\
\text { considered in conjunction with } \\
\text { coping time and any new failure } \\
\text { mode (initial conditions will be } \\
\text { concept specific). It is recognized } \\
\text { that concepts having more } \\
\text { restrictive initial conditions may } \\
\text { provide longer coping times. }\end{array}$ & $\begin{array}{l}\text { Same or less restrictive are desirable; } \\
\text { however, these should be considered } \\
\text { in conjunction with coping time and } \\
\text { any new failure mode (initial } \\
\text { conditions will be concept specific). } \\
\text { It is recognized that concepts having } \\
\text { more restrictive initial conditions may } \\
\text { provide longer coping times. }\end{array}$ \\
\hline $\begin{array}{l}\text { Reactivity management affect on } \\
\text { initial conditions }\end{array}$ & $\begin{array}{l}\text { Control rods, soluble boron, } \\
\text { burnable poisons combinations } \\
\text { must be optimized }\end{array}$ & $\begin{array}{l}\text { Control rods, soluble boron, burnable } \\
\text { poisons combinations must be } \\
\text { optimized }\end{array}$ \\
\hline Coping Time & \multicolumn{2}{|c|}{$\begin{array}{l}\text { How many hours are worth it? Should be compared to what you have now, } \\
\text { for example, if you have many hours of coping time, } 1 \text { or } 2 \text { additional might } \\
\text { not be worthwhile; however, if you only have a few the extra couple may be } \\
\text { significant. Days are worthwhile; hours maybe not? Minimum requirement } \\
\text { is } 6 \text { to } 8 \text { hours? It may be possible to develop a technical basis for the length } \\
\text { of time that is significant. For now, any longer is better. }\end{array}$} \\
\hline
\end{tabular}




\begin{tabular}{|c|c|c|}
\hline \multicolumn{3}{|l|}{ Transients \& Accidents } \\
\hline Subcategory & LTA/LTR (10 year objective) & Reload/Full Core \\
\hline $\begin{array}{l}\text { Minimum flow required to } \\
\text { stabilize the core without } \\
\text { significant hydrogen generation }\end{array}$ & $\begin{array}{l}\text { Must be evaluated in conjunction } \\
\text { with concept's oxidation kinetics. }\end{array}$ & $\begin{array}{l}\text { Must be evaluated in conjunction } \\
\text { with concept's oxidation kinetics. }\end{array}$ \\
\hline $\begin{array}{l}\text { Reactivity Insertion Accidents } \\
\text { (RIA), RIA cladding failure, } \\
\text { Loss-of-coolant accidents } \\
\text { (LOCA), Anticipated Transients } \\
\text { without Scram (ATWS), Current } \\
\text { design-basis LOCA limits, Fuel } \\
\text { and possible cladding } \\
\text { fragmentation / dispersal, Non- } \\
\text { LOCA cladding embrittlement, } \\
\text { Maintenance of coolable } \\
\text { geometry }\end{array}$ & Same performance or better. & Same performance or better. \\
\hline $\begin{array}{l}\text { Extended station blackout and } \\
\text { other severe accidents }\end{array}$ & $\begin{array}{l}\text { Improved coping time and } \\
\text { significantly reduced hydrogen } \\
\text { generation. }\end{array}$ & $\begin{array}{l}\text { Improved coping time and } \\
\text { significantly reduced hydrogen } \\
\text { generation. }\end{array}$ \\
\hline \multicolumn{3}{|c|}{ Licensing and Utility/Vendor considerations } \\
\hline Subcategory & LTA/LTR (10 year objective) & Reload/Full Core \\
\hline Performance predictions & $\begin{array}{l}\text { Qualified methods for design, } \\
\text { operations \& demonstrating } \\
\text { compliance and to evaluate the } \\
\text { impact of the LTAs on the rest of } \\
\text { the core. Mixed core effects. }\end{array}$ & $\begin{array}{l}\text { NRC approved methods for design, } \\
\text { operations \& demonstrating } \\
\text { compliance }\end{array}$ \\
\hline $\begin{array}{l}\text { Introduction of new failure } \\
\text { modes or conditions }\end{array}$ & $\begin{array}{l}\text { Failure modes and effects analysis } \\
\text { must be provided. }\end{array}$ & $\begin{array}{l}\text { Sufficient fundamental understanding } \\
\text { of the fuel failure modes and effects } \\
\text { and demonstrate no adverse } \\
\text { consequences relative to current fuel. } \\
\text { Consider initial conditions for } \\
\text { accident scenarios. }\end{array}$ \\
\hline \multicolumn{3}{|c|}{ icensing and Utility/Vendor considerations } \\
\hline Subcategory & LTA/LTR (10 year objective) & Reload/Full Core \\
\hline $\begin{array}{l}\text { Supporting Material performance } \\
\text { information. }\end{array}$ & $\begin{array}{l}\text { Test reactor data and relevant out- } \\
\text { of-pile information. }\end{array}$ & $\begin{array}{l}\text { Availability of material information } \\
\text { for licensing }\end{array}$ \\
\hline Manufacturability & $\begin{array}{l}\text { Provide substantiation that } \\
\text { commercial quantities can be } \\
\text { produced economically. }\end{array}$ & $\begin{array}{l}\text { Provide substantiation that } \\
\text { commercial quantities can be } \\
\text { repeatability produced economically. } \\
\text { NDE techniques and capabilities } \\
\text { should be established. }\end{array}$ \\
\hline Reliability & $\begin{array}{l}\text { want to maintain zero leaker } \\
\text { philosophy }\end{array}$ & $\begin{array}{l}\text { want to maintain zero leaker } \\
\text { philosophy }\end{array}$ \\
\hline $\begin{array}{l}\text { Need for higher enrichment and } \\
\text { corresponding infrastructure is } \\
\text { perceived as a large obstacle by } \\
\text { the nuclear industry. }\end{array}$ & $\begin{array}{l}\text { Enrichments }=<5 \mathrm{wt} \% \text { preferred } \\
\text { due to limitations imposed by } \\
\text { current infrastructure in the near } \\
\text { term }\end{array}$ & $\begin{array}{l}\text { Enrichments }=<5 \mathrm{wt} \% \text { preferred due } \\
\text { to limitations imposed by current } \\
\text { infrastructure in the near term }\end{array}$ \\
\hline
\end{tabular}




\begin{tabular}{|c|c|c|}
\hline $\begin{array}{l}\text { Evolutionary versus } \\
\text { revolutionary }\end{array}$ & $\begin{array}{l}\text { Evolutionary approaches to } \\
\text { demonstration of concepts are } \\
\text { preferred. LTAS should be } \\
\text { representative of the full core } \\
\text { design wherever possible. }\end{array}$ & $\begin{array}{l}\text { Evolutionary approaches to } \\
\text { demonstration of concepts are } \\
\text { preferred. LTAS should be } \\
\text { representative of the full core design } \\
\text { wherever possible. }\end{array}$ \\
\hline \multicolumn{3}{|l|}{ Other improvement considerations } \\
\hline Subcategory & LTA/LTR (10 year objective) & Reload/Full Core \\
\hline $\begin{array}{l}\text { Eliminate other zirc alloy } \\
\text { components }\end{array}$ & N/A & $\begin{array}{l}\text { BWR Zirc alloy fuel channels } \\
\text { Instrument channel } \\
\text { guide tubes } \\
\text { spacer grids }\end{array}$ \\
\hline \multicolumn{3}{|l|}{ Other improvement considerations } \\
\hline Subcategory & LTA/LTR (10 year objective) & Reload/Full Core \\
\hline $\begin{array}{l}\text { Recognize that other core } \\
\text { components could melt before } \\
\text { zirc-clad UO2 fuel damage } \\
\text { occurs, while still maintaining } \\
\text { coolable geometry and } \\
\text { containment boundary. }\end{array}$ & N/A & $\begin{array}{l}\text { Changes may be needed on control } \\
\text { components and eutectics thereof } \\
\text { (blades, spiders, burnable poisons) }\end{array}$ \\
\hline $\begin{array}{l}\text { Maintaining additional margin } \\
\text { supplied by ATF }\end{array}$ & N/A & $\begin{array}{l}\text { Will margins provided be consumed } \\
\text { by utilities with power uprates, } \\
\text { thereby eliminating the additional } \\
\text { margin? If hydrogen generation is } \\
\text { reduced by the ATF, then this alone is } \\
\text { considered a benefit. }\end{array}$ \\
\hline Neutron absorbers & $\begin{array}{l}\text { Ensure manufacturability and } \\
\text { operation of neutron absorbers, } \\
\text { especially those that are integral to } \\
\text { the fuel system, to ensure } \\
\text { performance during all operating } \\
\text { conditions. }\end{array}$ & $\begin{array}{l}\text { Ensure manufacturability and } \\
\text { operation of neutron absorbers, } \\
\text { especially those that are integral to } \\
\text { the fuel system, to ensure } \\
\text { performance during all operating } \\
\text { conditions. }\end{array}$ \\
\hline \multicolumn{3}{|l|}{ Fuel Cycle considerations } \\
\hline Subcategory & LTA/LTR (10 year objective) & Reload/Full Core \\
\hline Reprocessing capability & not addressed in this session. & not addressed in this session. \\
\hline Shipping \& handling & not addressed in this session. & not addressed in this session. \\
\hline Storage \& disposal & not addressed in this session. & not addressed in this session. \\
\hline \multicolumn{3}{|l|}{ Economics } \\
\hline Subcategory & LTA/LTR (10 year objective) & Reload/Full Core \\
\hline Cost of enhanced fuel & $\begin{array}{l}\text { Compensated cost for utility? } \\
\text { Possible lower power generated? } \\
\text { What about fuel failure that may be } \\
\text { a result of the LTA. } \\
\text { Require test irradiations, loop } \\
\text { testing, statistically meaningful } \\
\text { testing. }\end{array}$ & $\begin{array}{l}\text { Willing to pay somewhat more for } \\
\text { better accident performance with } \\
\text { same normal operating performance. } \\
\text { Plants are having to upgrade other } \\
\text { components such hydrogen vents, } \\
\text { batteries, etc. }\end{array}$ \\
\hline
\end{tabular}




\section{References}

DOE Accident Tolerant Fuels Roadmap - Pending approval

Goldner, Frank, "Development Strategy for advanced LWR Fuels with Enhanced Accident Tolerance," Presentation to Enhanced Accident Tolerant LWR Fuels National Metrics Workshop, October 10, 2012.

Griffith, Andy, "Related NE R\&D Activities," Presentation to Enhanced Accident Tolerant LWR Fuels National Metrics Workshop, October 10, 2012.

Pasamehmetoglu, Kemal, “Accident Tolerant Fuels: Development of Metrics, Workshop Expectations," Presentation to Enhanced Accident Tolerant LWR Fuels National Metrics Workshop, October 10, 2012. 


\section{Appendix A: Agenda}




\section{AGENDA}

\section{Wednesday, October 10, 2012}

\begin{tabular}{|c|c|c|}
\hline $8: 00$ & Arrive at Conference Room & \\
\hline $8: 30$ & Welcome/Introductions & Kemal Pasamehmetoglu \\
\hline 9:00 & $\begin{array}{l}\text { Enhanced Accident Tolerant Fuels Overview } \\
\text { History, Definition, Mission, Objectives }\end{array}$ & Frank Goldner \\
\hline $9: 30$ & FOAs and IRPs & Andy Griffith \\
\hline 10:00 & Break & \\
\hline $10: 30$ & $\begin{array}{l}\text { Attributes for Fuels with Enhanced Accident } \\
\text { Tolerance/Constraints/Workshop Outcomes }\end{array}$ & Kemal Pasamehmetoglu \\
\hline $11: 00$ & Integrated Accident Testing Analysis Leading to Metrics & Larry Ott \\
\hline $11: 20$ & Breakout Session Process & Lori Braase \\
\hline $11: 30$ & Lunch & \\
\hline \multirow[t]{4}{*}{ 1:00 } & Breakout Sessions & \\
\hline & $\begin{array}{l}\text { 1. Improved Reaction Kinetics with Steam/Slower } \\
\text { Hydrogen Generation Rate/Cladding Thermo- } \\
\text { Mechanical Properties }\end{array}$ & Shannon Bragg-Sitton \\
\hline & $\begin{array}{l}\text { 2. Improved Fuel and Cladding Thermo-Mechanical } \\
\text { Properties/Fission Product Retention }\end{array}$ & Chris Stanek \\
\hline & $\begin{array}{l}\text { 3. Constraints: Current LWR Designs/Operational and } \\
\text { Safety Envelope/Economic Impacts/ Definition of } \\
\text { Representative Accident Scenario. }\end{array}$ & Rose Montgomery \\
\hline $5: 30$ & Adjourn & \\
\hline
\end{tabular}




\section{AGENDA}

\section{Thursday, October 11, 2012}

8:00 Arrive at Conference Room

Breakout Sessions: Status Reports

$8: 30$

$8: 50$

$9: 10$

9:30 Resume Breakout Sessions

11:30 Lunch

1:00 Breakout Sessions: Prepare Summaries

Breakout Sessions: Summary Presentations

2:30 1. Improved Reaction Kinetics with Steam/Slower

$3: 15$

4:00

4:45 Discussion: Summary and Path Forward 5:30 Adjourn
Session Leads

Shannon Bragg-Sitton

Chris Stanek

Rose Montgomery Hydrogen Generation Rate/Cladding ThermoMechanical Properties

Session Leads

Shannon Bragg-Sitton

Chris Stanek

Rose Montgomery Safety Envelope/Economic Impacts/Definition of Representative Accident Scenario. Properties/Fission Product Retention

3. Constraints: Current LWR Designs/Operational and

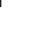
- Improved Kinetics/Slower Hydrogen Gen/Cladding

- Constraints: LWR Designs/Safety/Economics

Shannon Bragg-Sitton 


\section{Appendix B: Presentations}

- Development Strategy for Advanced LWR Fuels with Enhanced Accident Tolerance (F. Goldner)

- Related NE R\&D Activities (A. Griffith)

- Accident Tolerant Fuels: Development of Metrics, Workshop Expectations

(K. Pasamehmetoglu)

- Integrated Accident Testing Analysis Leading to Metrics (L. Ott) 


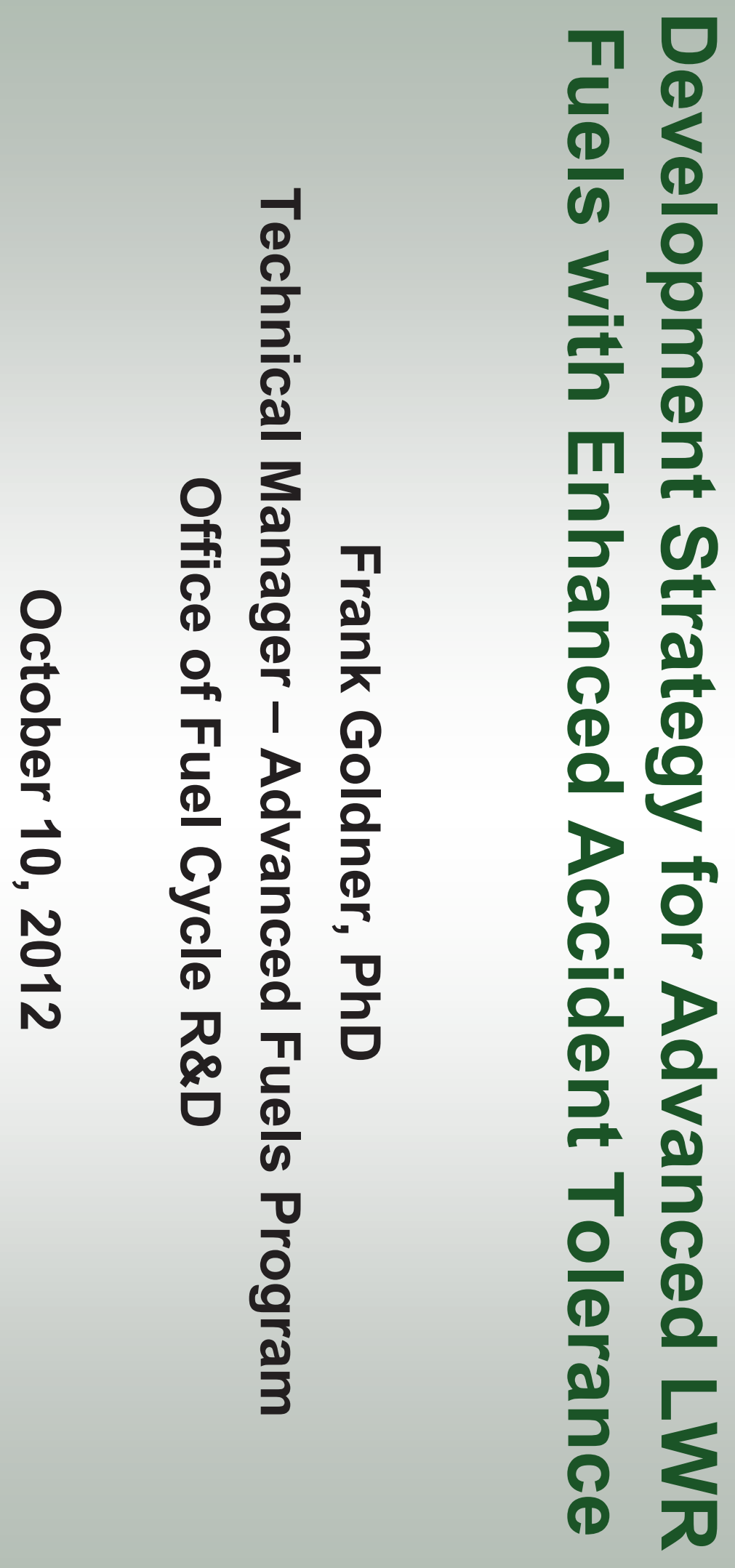




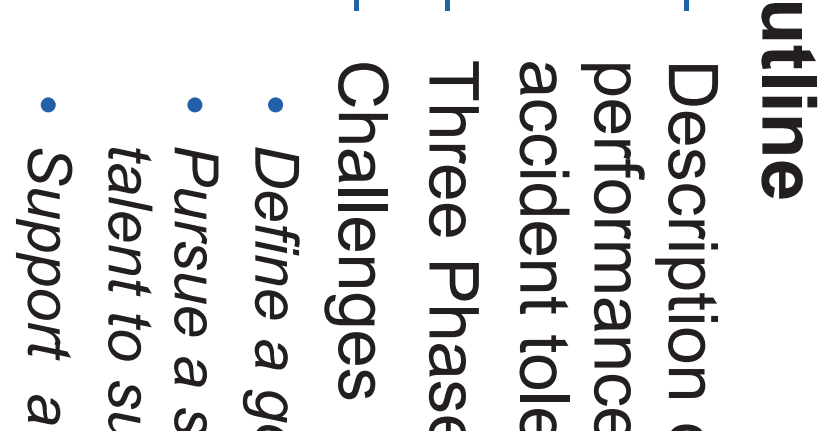

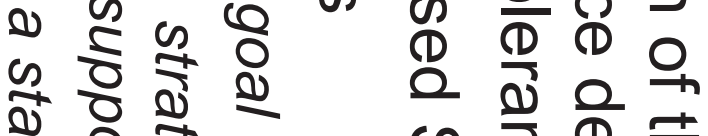

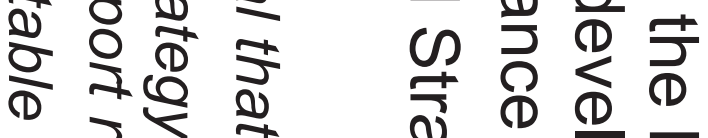

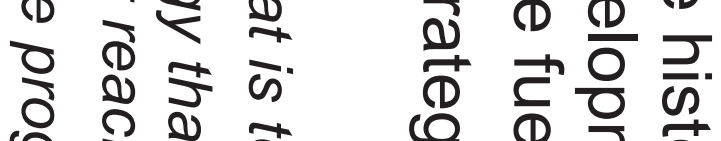

용

ริ

ㅇำ

(ర)

인

D

:

N

क व

) $\frac{8}{10}$

产

Q

유요

市

응

윽 잉

줄으

웅

จ

$\stackrel{\overbrace{}}{\rightleftharpoons}$. 듯

ه

O $\stackrel{\text { D }}{<}$

ర

Ф

(D)

난

穴守 完

D

믐 긍.

들융 웅 웅

面

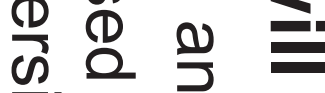

承

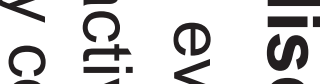

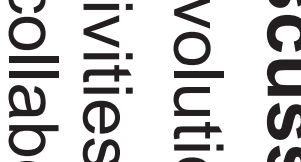

ठㅇ ڤ

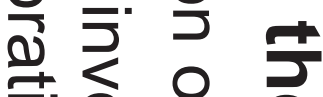

음 응 으

市

क

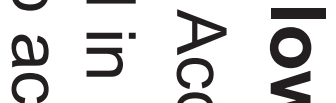

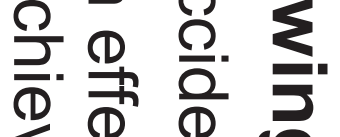

অ

ब( $\stackrel{2}{\stackrel{1}{2}}$

ข

음 잉 응

욜

六 $\frac{2}{2}$ ?

$\stackrel{2}{2}$

ำ

อิ

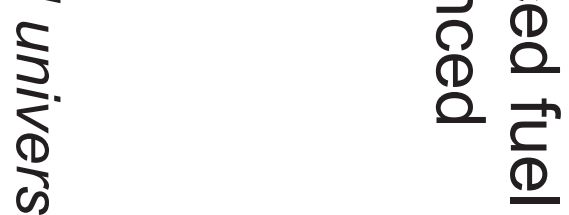

으은

(a) T

일 몬

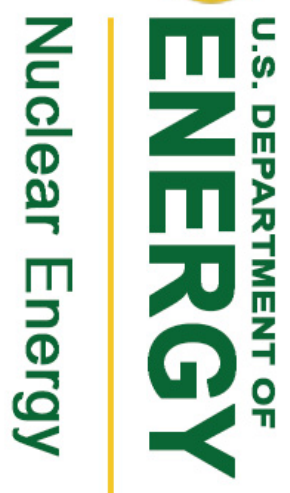

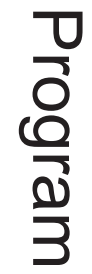



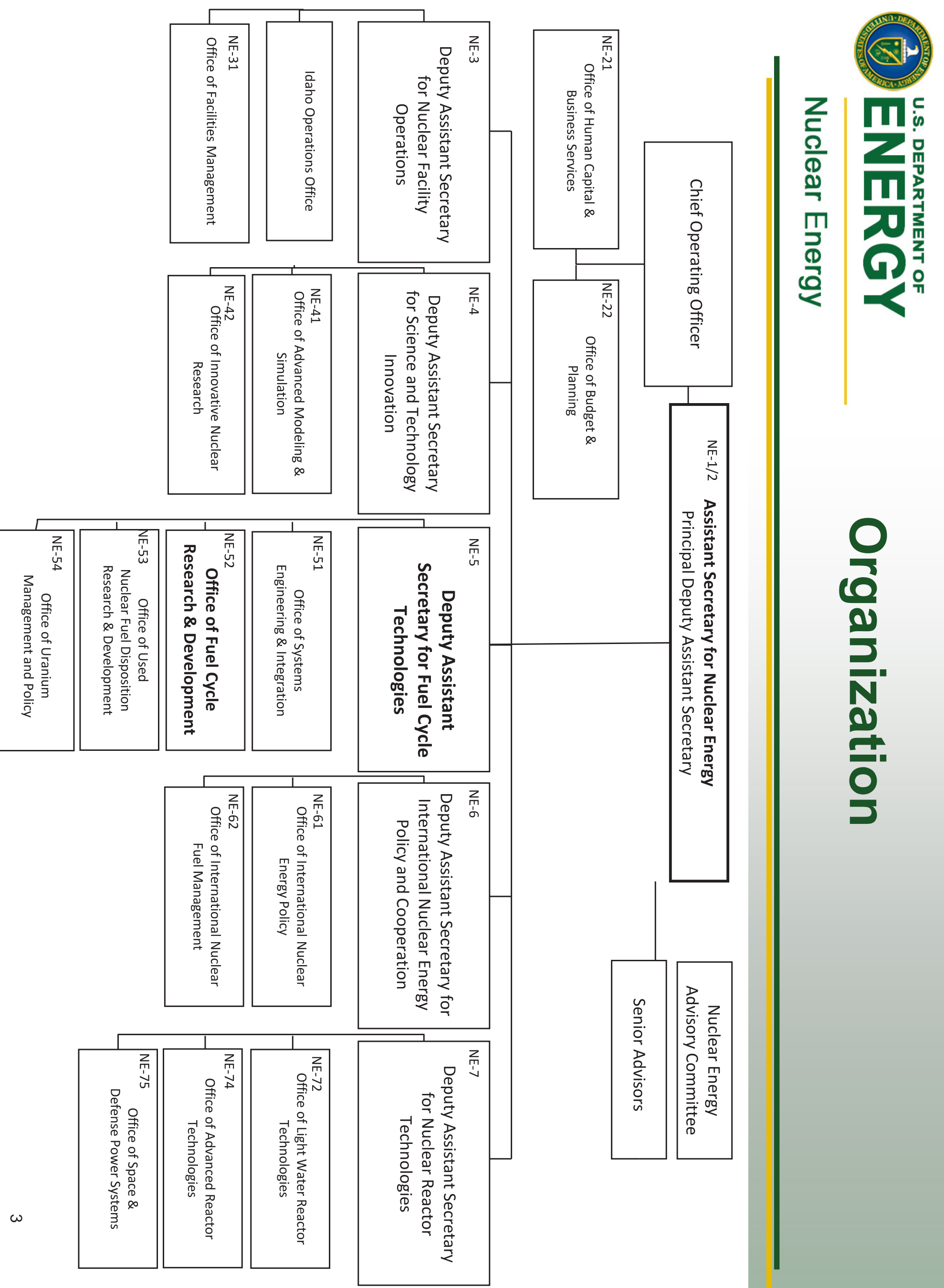


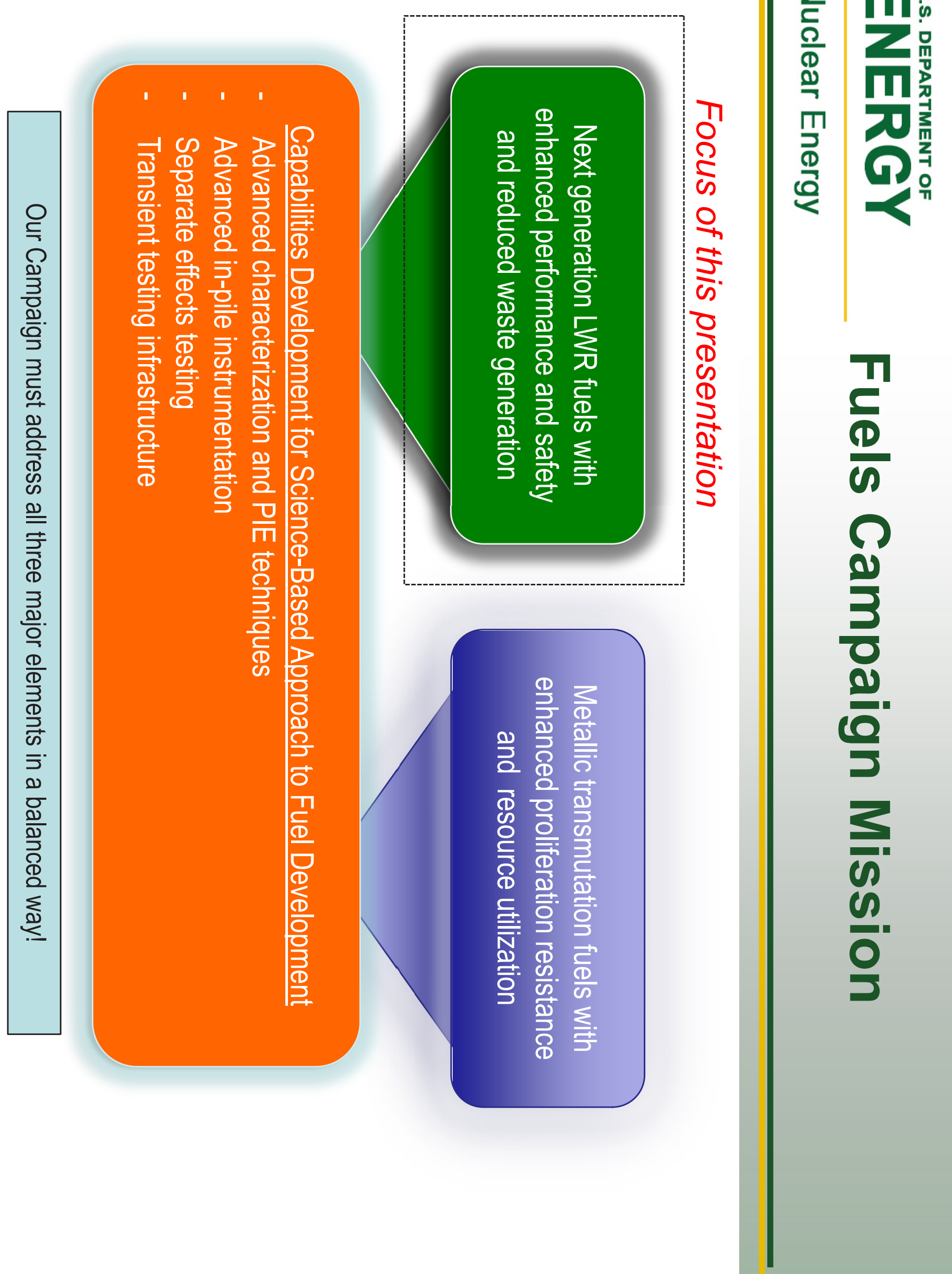




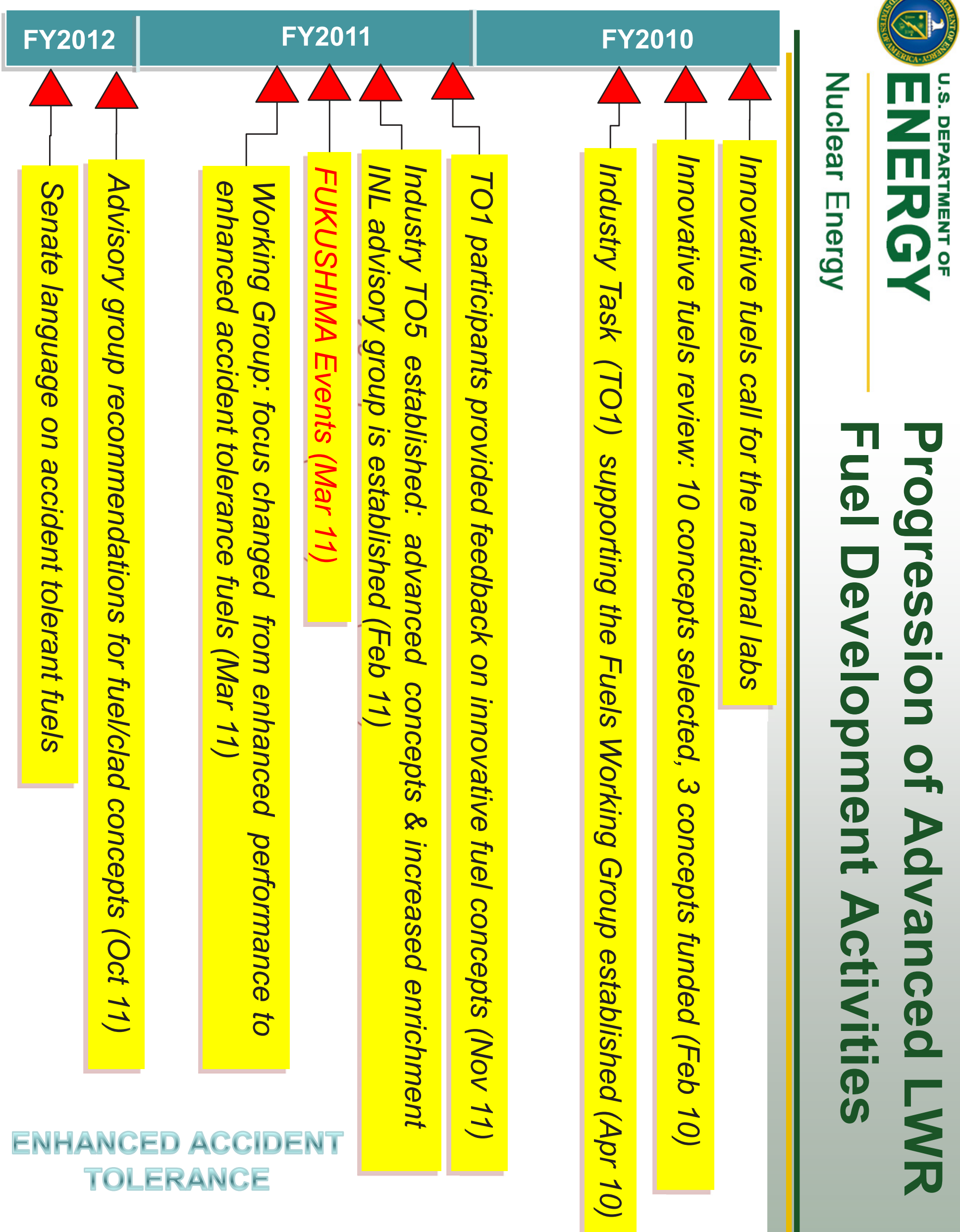




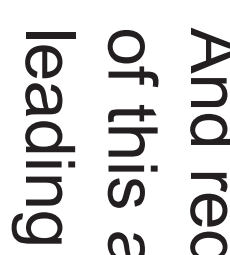

ठ $\stackrel{0}{\stackrel{0}{\circ}}$

त)

(1)

$\stackrel{9}{F} 0$

응 के

त)

(⿻)

훙음 욱

응 웅

드웅

등

충 웅

홍 용

웅용

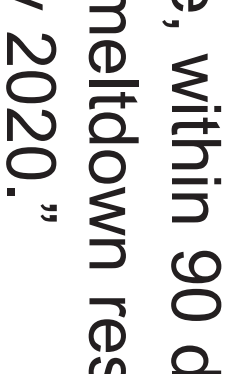

क. ํํㄹ

बे के

고 으

름

$\frac{\bar{D}}{\omega} \stackrel{2}{\stackrel{0}{2}}$

$\frac{\stackrel{3}{3}}{3}$

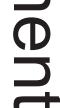

菑 공 ڤ

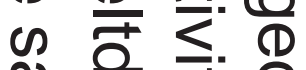

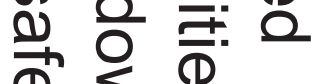

ब)

₹

오

응 $\frac{\omega}{\omega} \stackrel{0}{0}$

ه

(1) $\stackrel{0}{\rightleftharpoons}$

람

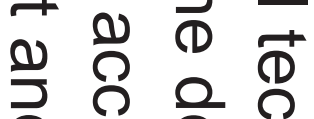

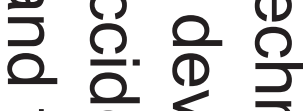

류

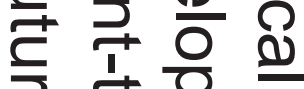

후응 응

요 $\mathbb{D} 3$

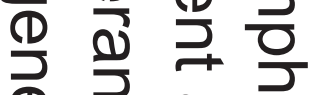

Ф

을 글

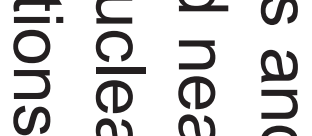

क ஹू ฏ

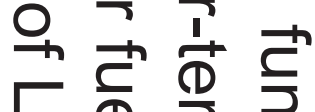

둥 용 을

두음

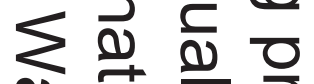

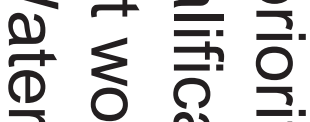

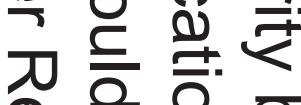

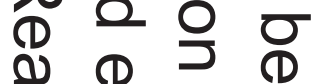

웡 궁요을.

के

ఠ

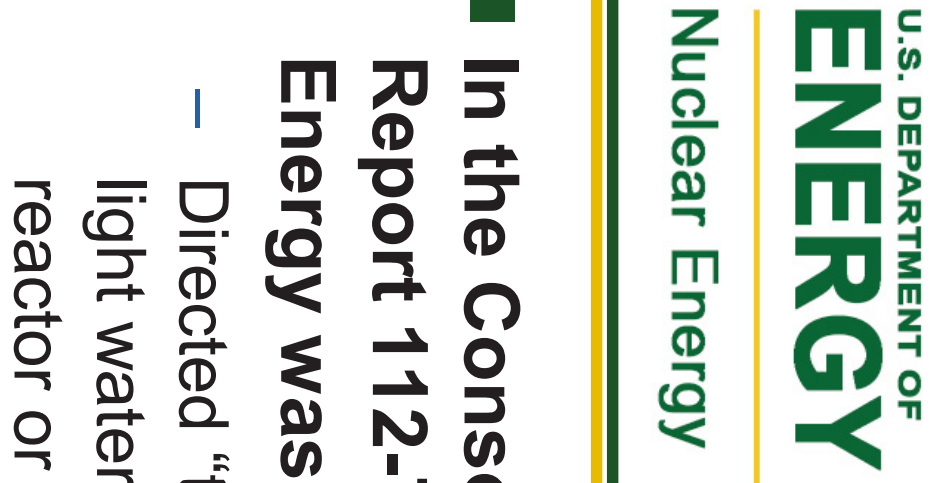

क ठै

㗕

롱응

응 흥.

쿠 ₹

क 흐 o

$=$ 응

¿

()

$\stackrel{0}{\vec{D}}$ 음

吝 $\frac{0}{3}$.

5.

穴 $\frac{\text { D }}{\frac{1}{9}}$

(1)

依

$\stackrel{\mathbb{D}}{2}$

올

(1) $\frac{D}{\infty}$

ก

을 을

造 $\frac{2}{0}$

긍

푸 을

خิธ

节

(1) 8

용

응

국응

음

ำ

웅

m

จ

눈

옹

㭧

ก

8

8

옥옥

Z

도

ล

ธิ

(1) (D) $\nabla \omega$

ก (D

$\Omega 5$

ㅇ

음

(D) $D$
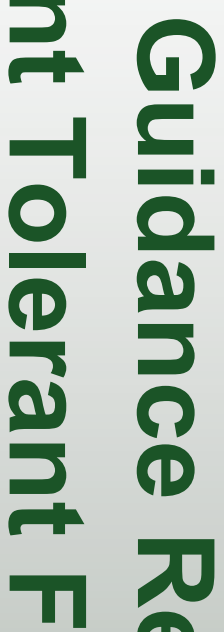

(D)

(O)

(D) 


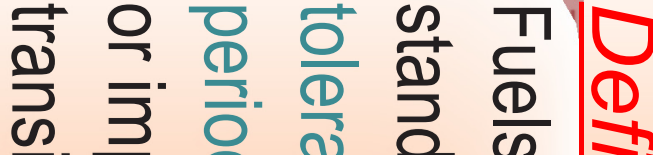

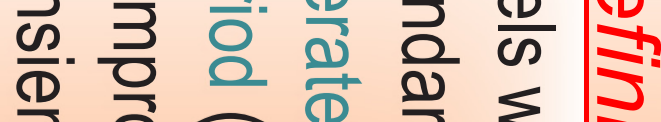

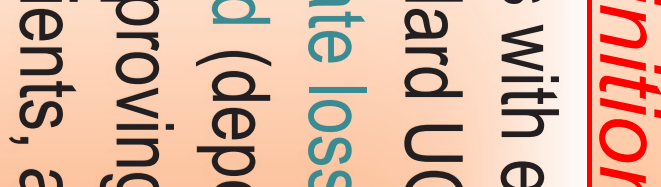

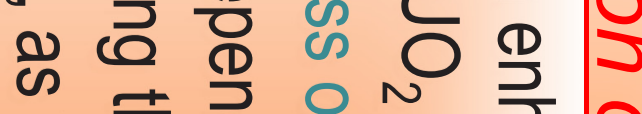

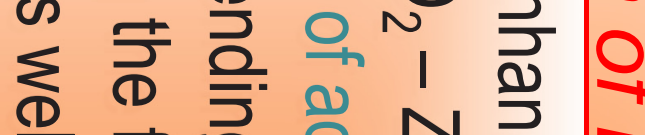

$$
\begin{aligned}
& \text { 焉 } \\
& \text { 응 궁 } \\
& \text { 뜩 윽 位 }
\end{aligned}
$$

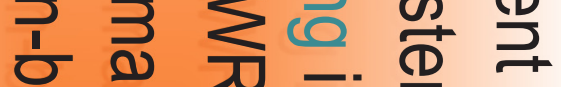

$$
\begin{aligned}
& \text { कै क }
\end{aligned}
$$

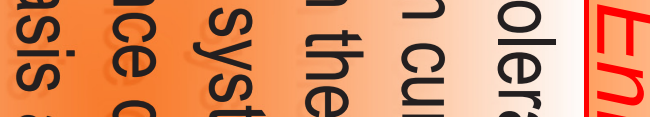

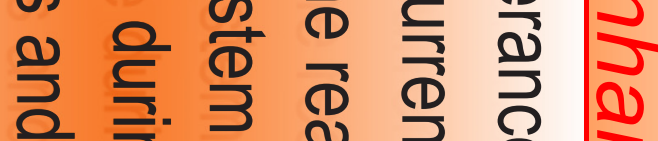

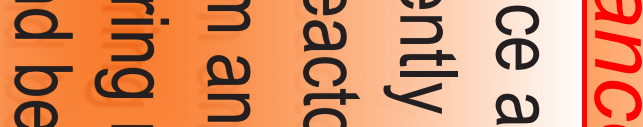

$$
\begin{aligned}
& \text { 긍으요 } \\
& \text { 을 을 응 } \frac{1}{D} \text { D } \\
& \text { 드공요응 응 }
\end{aligned}
$$

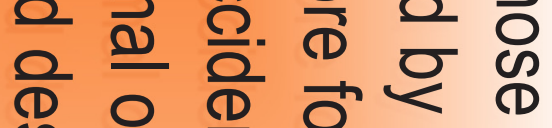

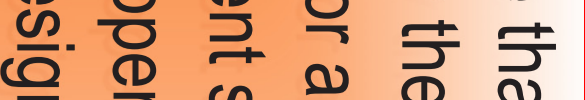

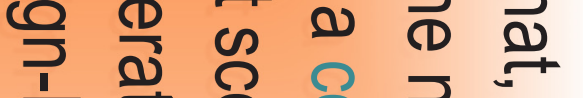

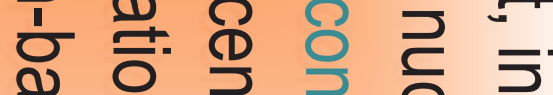

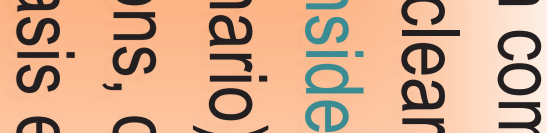

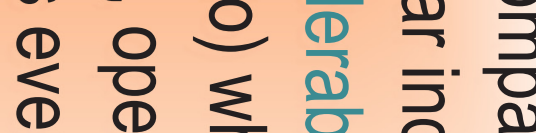

$$
\begin{aligned}
& \text { Ф } \Phi \text { 홍ㅎㅇ }
\end{aligned}
$$

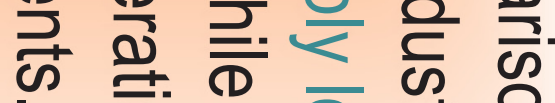

$$
\begin{aligned}
& \text { 흑 곡올 욱 } \\
& \text { 일 용 } \\
& \text { 可 号 }
\end{aligned}
$$

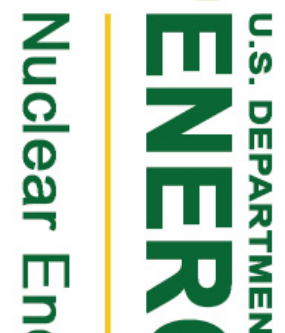

通 


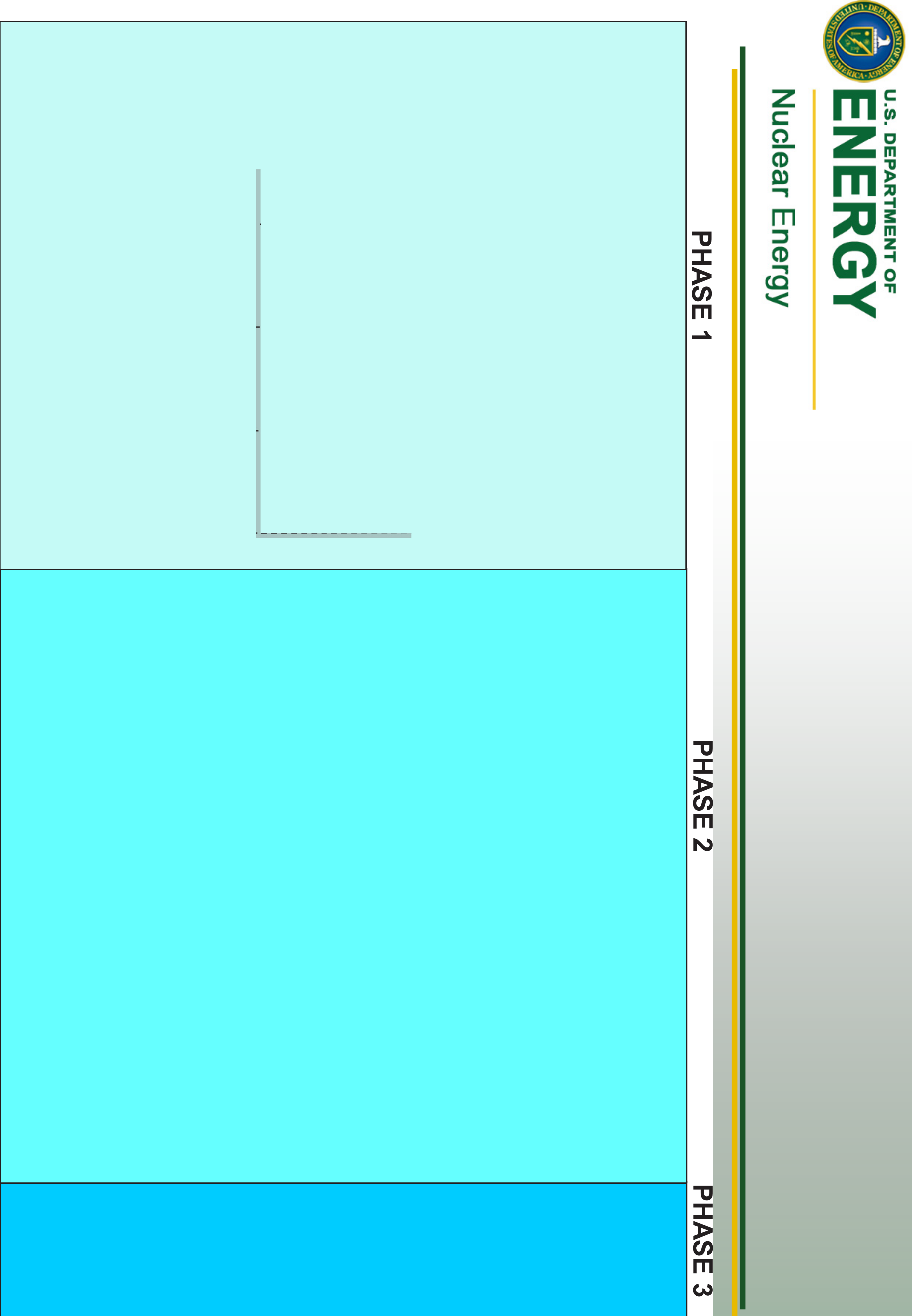

